\title{
$\pi$-Alkene/Alkyne and Carbene Complexes of Gold(I) Stabilized by Chelating Ligands
}

\author{
Miquel Navarro, ${ }^{\#}$ Didier Bourissou* \\ CNRS / Université Paul Sabatier, Laboratoire Hétérochimie Fondamentale et Appliquée (LHFA, \\ UMR 5069). 118 Route de Narbonne, 31062 Toulouse Cedex 09 (France). \\ \#Current address: Instituto de Investigaciones Químicas (IIQ), Departamento de Química \\ Inorgánica and Centro de Innovación en Química Avanzada (ORFEO-CINQA). Consejo Superior \\ de Investigaciones Científicas (CSIC) and University of Sevilla. Avenida Américo Vespucio 49, \\ 41092 Sevilla (Spain).
}

*Corresponding author, email address: dbouriss@chimie.ups-tlse.fr

\section{Contents}

1. Introduction and scope

2. $\operatorname{Gold}(\mathrm{I}) \pi$-complexes

2.1 Gold(I) $\pi$-complexes with $N^{\wedge} N$-chelating ligands

2.2 Gold(I) $\pi$-complexes with $P^{\wedge} P$ and $P^{\wedge} N$-chelating ligands

2.3 Comparison of Gold(I) ethylene complexes with chelating and hemilabile ligands

3. Gold(I) carbene complexes

4. Concluding remarks

\section{Abstract}

Long overlooked, chelating ligands have garnered recently increasing interest in gold chemistry. They enforce bending at gold(I) and thereby, noticeably modify its electronic properties. This review focuses on $\pi$-complexes with alkenes and alkynes side-on coordinated to gold(I), as well as gold(I) carbene complexes. The influence of the chelating ligand on the structure, bonding and reactivity of these species is thoroughly discussed.

\section{Keywords}

Carbene / gold / bidentate ligand / $\pi$-complex / alkene / alkyne / bonding / NMR spectroscopy / X-ray diffraction / DFT calculations 


\section{Introduction}

The use of gold in homogenous catalysis was scarcely investigated during the last century, since gold complexes were long considered to be chemically inert and thus catalytically useless species. This situation changed dramatically when the carbophilic properties of gold complexes were discovered, and within only two decades, they became extremely powerful and versatile catalysts for the activation and functionalization of $\pi$-CC bonds. ${ }^{1}$ Accordingly, a number of useful catalytic transformations in organic synthesis based on $\pi$ - or $\sigma, \pi$-coordination of alkynes, allenes and alkenes have been developed. ${ }^{2}$ These advances in gold-catalyzed transformations have stimulated coordination and organometallic studies in order to gain more understanding of the structure and reactivity of gold complexes, in particular gold(I) species. Here, monodentate ligands, especially phosphines and $\mathrm{N}$-Heterocyclic carbenes (NHCs), have been extensively used as ancillary ligands due to the inherent preference for gold(I) complexes to be two-coordinate and adopt linear geometry. ${ }^{3}$ In contrast, gold(I) complexes featuring bidentate ligands are comparatively very rare, but have captured increasing attention because of the unique properties chelating ligands impart to gold in terms of bonding and chemical behavior. From a structural point of view, bidentate ligands force gold(I) to escape its usual two-coordinate linear form and they are preorganized to form tri or even tetra-coordinate complexes. ${ }^{4}$ In addition, chelating ligands enforce bending at gold and thereby, noticeably modify its electronic properties. Most significant is the impact on the energy and symmetry of the frontier orbitals. As illustrated in Figure 1 for model phosphine and diphosphine cationic gold(I) complexes, the HOMO is very much raised in energy and changes from $5 \mathrm{~d}_{\mathrm{z} 2}$ to $5 \mathrm{~d}_{\mathrm{xz}}$ in symmetry, in line with that encountered in group $10 \mathrm{ML}_{2}$ complexes. $^{5}$ In the meantime, the LUMO is raised in energy, but remains low. Overall, the energy gap between the vacant and occupied orbitals at gold involved in donation and backdonation (HOMO3/LUMO for the monophosphine complex, HOMO/LUMO for the diphosphine complex) is considerably decreased. 


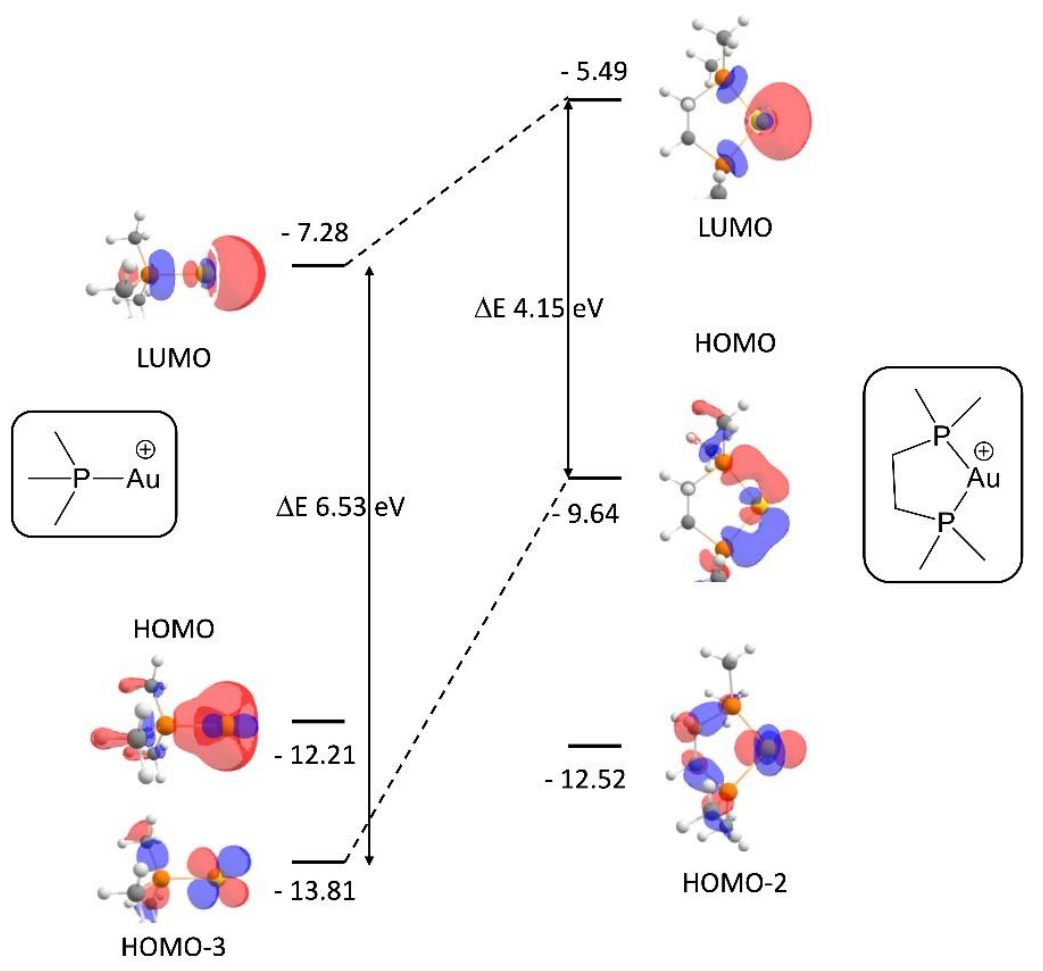

Figure 1. Frontier orbitals of model gold(I) complexes bearing monodentate and bidentate phosphine ligands.

The unique properties of bent dicoordinate $\mathrm{L}_{2} \mathrm{Au}^{+}$fragments was shown to radically impact oxidative addition to gold. This elementary step is hardly feasible with monocoordinate $\mathrm{Au}(\mathrm{I})$ complexes, ${ }^{6,7,8,9}$ and the reluctance of gold to cycle between the $+\mathrm{I}$ and $+\mathrm{III}$ oxidation states has limited its application in such catalytic transformations. However, when the metal fragment is activated and preorganized thanks to the use of a chelating ligand, oxidative addition to gold turns easy and general, ${ }^{10,11,12,13,14}$ opening new avenues in $\mathrm{Au}(\mathrm{I}) / \mathrm{Au}(\mathrm{III})$ catalysis. ${ }^{12,15,16,17,18,19,20,21}$

In this review are discussed the preparation, characterization, structure and reactivity of two types of gold(I) complexes featuring chelating ligands: first, $\pi$-complexes with alkenes and alkynes side-on coordinated, and then carbene complexes. A small library of chelating ligands of $\mathrm{L}^{\wedge} \mathrm{L}(')$, $L^{\wedge} E^{(-)} L$ and $L^{\wedge} X$ types have been exploited in gold(I) chemistry to date (Figure 2). With this detailed survey, we hope to inspire the gold community and newcomers to further use and develop chelating ligands in gold(I) chemistry. There is clearly still a lot to discover. 

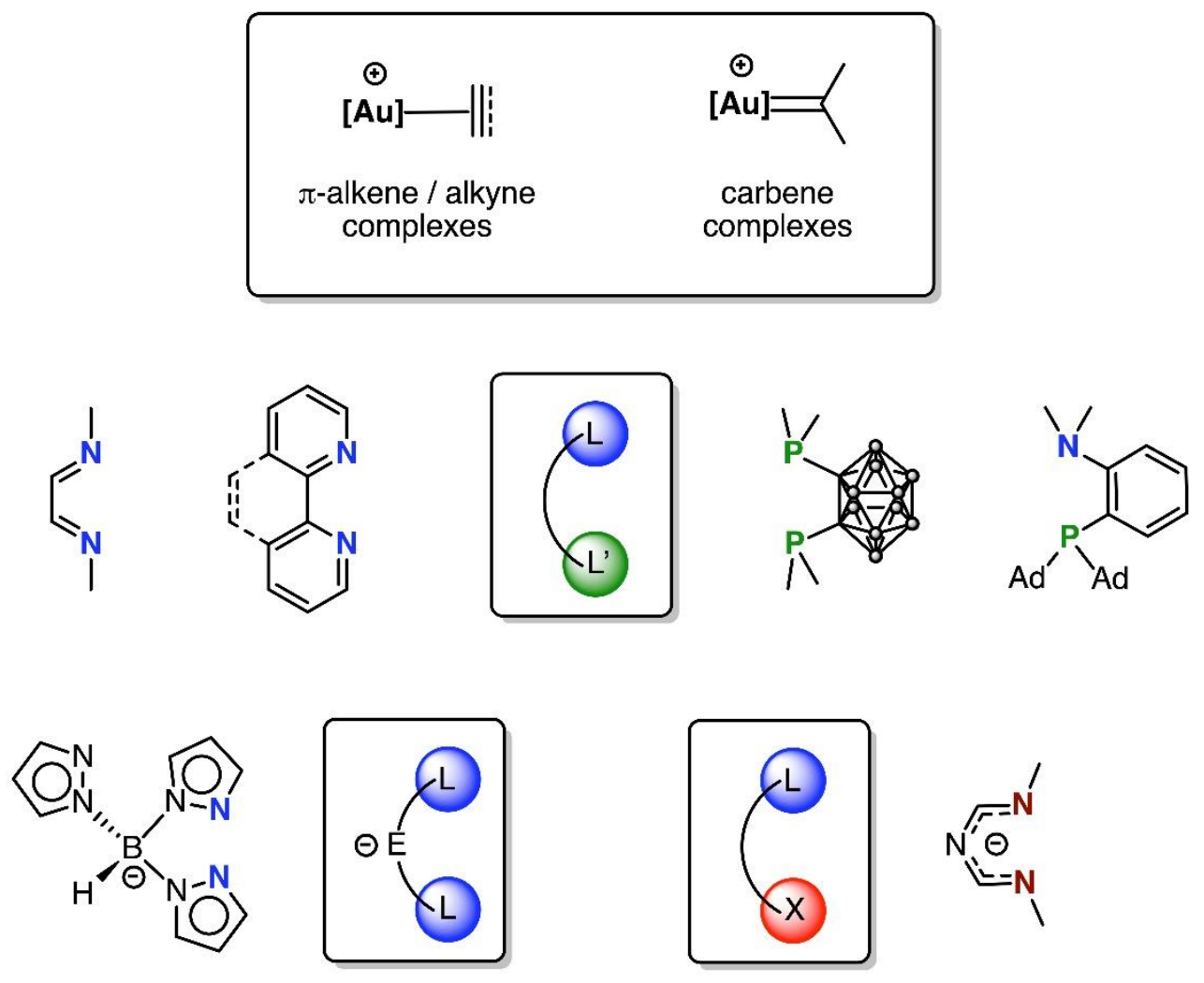

Figure 2. Scope of the review and schematic representation of the chelating ligands involved.

\section{Gold(I) $\pi$-complexes}

As mentioned above, the discovery of the ability of gold complexes to activate $\pi$-bonds towards nucleophilic addition has represented a great breakthrough in homogeneous catalysis and in organic synthesis. ${ }^{2,22,23,24,25,26}$ A large number of useful transformations such as the addition of oxygen-, nitrogen-, and carbon-based nucleophiles to CC multiple bonds, rearrangements and cycloaddition reactions have been developed. ${ }^{27,28,29,30,31,32}$ All these catalytic transformations usually involve the side-on coordination and activation of a $\pi$-CC bond to gold. Consequently, the isolation of gold $\pi$-complexes has received considerable attention in the last two decades. ${ }^{33,34,35,36,37}$ These compounds serve as models for the transient species and their study provide valuable insights into the factors governing the catalytic transformations. Since the determination of the crystal structure of the Zeise's salt $1 \mathrm{~K}\left[\mathrm{Cl}_{3} \mathrm{Pt}\left(\mathrm{C}_{2} \mathrm{H}_{4}\right)\right],{ }^{38}$ major efforts were made in order to mimic the platinum behavior to coordinate olefins. After several attempts and non-conclusive studies to isolate and characterize stable gold(I) complexes with a coordinated olefin, the group of Strähle in 1987 finally isolated and structurally characterized the first $\mathrm{Au}(\mathrm{I})$ $\pi$-complex 2, with cis-cyclooctene coordinated to $\mathrm{AuCl}$ (Figure 3).$^{39}$ The $\mathrm{C}=\mathrm{C}$ distance is 
significantly longer than in the free olefin ligand (1.38(2) $\AA$ versus $1.332(2) \AA)$, and the $v(\mathrm{C}=\mathrm{C})$ stretching vibration appears at $1525 \mathrm{~cm}^{-1}$, compared to $1648 \mathrm{~cm}^{-1}$ for the free olefin. A few years later, Fackler reported the tetranuclear complex 3 of the formula $\mathrm{Au}_{4}(\mathrm{dppe})_{2}\left[\mathrm{~S}_{2} \mathrm{C}_{2}(\mathrm{CN})_{2}\right] \mathrm{Cl}_{2}{ }^{40}$ Here, one of the four gold(I) centers is attached to the central $\mathrm{C}=\mathrm{C}$ bond of a cisbis(diphenylphosphino)-ethene (ddpe) and chelated by a 1,2-dicyanoethene-1,2-dithiolate ligand, thus presenting a formal negative charge. The $\mathrm{C}=\mathrm{C}$ bond sits in the $\mathrm{SAuS}$ coordination plane, enabling stabilizing interaction between the olefin $\pi^{*}$ and the metal $\mathrm{d}_{\pi}$ orbitals. The $\mathrm{C}=\mathrm{C}$ bond distance in complex 3 is elongated in comparison with the free olefin (1.38(6) A versus 1.30(6) $\AA$ ) indicating an important gold $\rightarrow \pi^{*}$ backdonation. In the following years, some $\pi$-alkyne gold(I) compounds were also reported. ${ }^{41,42,43,44}$<smiles>OC/C=C\P(Cl)(Cl)(Cl)Cl</smiles>

1

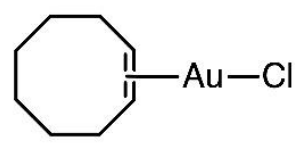

2

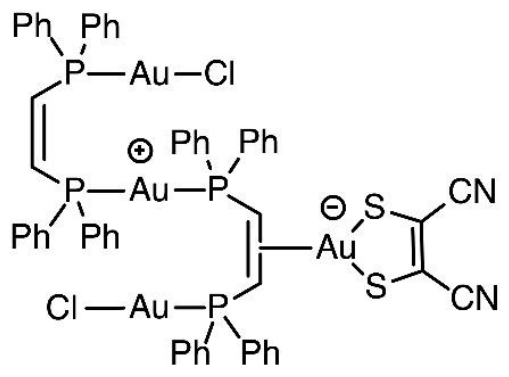

3

Figure 3. Zeise's salt 1, first isolated and structurally characterized $\mathrm{Au}(\mathrm{I})$ olefin complexes $\mathbf{2}$ and 3.

The isolation and characterization of the first gold(I) $\pi$-complexes have stimulated studies on olefin coordination to gold in different oxidation states. Theoretical investigations have shown that the bonding of ethylene and acetylene to gold(0) atoms is very weak, ${ }^{45,46}$ in contrast with initial experimental results. ${ }^{47,48,49,50,51}$ The binding energies are close to those of dispersion forces and gold $(0)$ has low affinity for $\mathrm{C}=\mathrm{C}$ and $\mathrm{C} \equiv \mathrm{C}$ bonds. On the other hand, gold(III) $\pi$-complexes featuring alkenes, alkynes and arenes are known, but rare. ${ }^{37}$ The weakness of the $\pi$-coordination to gold(III), due in part to the weak $\mathrm{Au} \rightarrow \pi^{*}$ backdonation, makes the study of such complexes challenging. This field is still in its infancy and much remains to be done. Most of the gold(III) $\pi$-complexes reported to date derive from cyclometallated ligands. They have been isolated or spectroscopically characterized in situ at low temperature $\left(<0^{0}{ }^{\circ} \mathrm{C}\right)$ under inert conditions. ${ }^{52,53,54,55,56,57}$

Cationic dicoordinate gold(I) $\pi$-complexes of the type $[\mathrm{LAu}(\mathrm{ene})]^{+}$represent the majority of the known gold $\pi$-complexes. They are generally stable both in the solid state and in solution. In most 
cases, $\mathrm{N}$-heterocyclic carbenes $(\mathrm{NHCs})^{58,59,60}$ or phosphines ${ }^{58,61,62,63,64}$ have been employed as ancillary ligands. The involved $\pi$-systems include alkenes, alkynes, conjugated dienes, allenes, enamines and enol ethers (Figure 4). Tricoordinate species have also been reported with different chelating ligands. They present unique features, but remain very scarce. In this section, tricoordinate gold(I) $\pi$-complexes bearing chelating or hemilabile ligands are reviewed in detail. Special attention is given to the specific electronic and structural features of the gold(I) $-\pi$-system interaction. The impact of this unusual coordination on the alkene/alkyne properties is discussed and compared with that encountered classically in cationic dicoordinate gold(I) $\pi$-complexes.
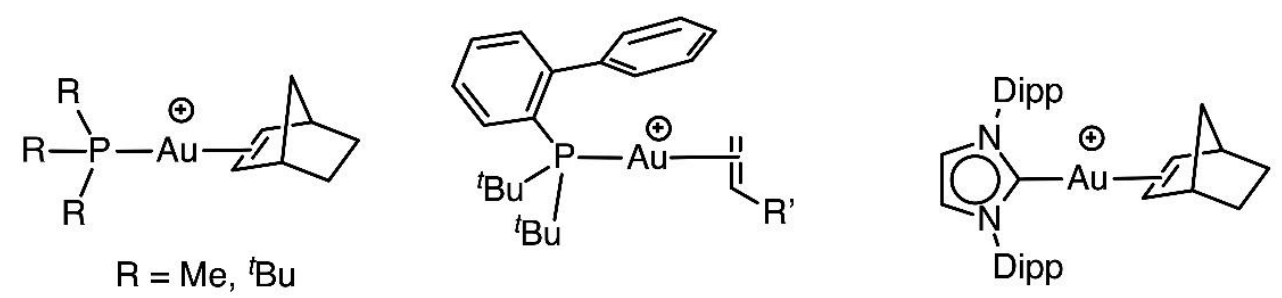

$$
\mathrm{R}^{\prime}=\mathrm{Ph},{ }^{n} \mathrm{Bu}
$$

Figure 4. Representative examples of selected NHC and phosphine $\pi$-alkene gold(I) complexes.

\subsection{Gold(I) $\pi$-complexes with $N^{\wedge} N$-chelating ligands}

In the mid 2000's, Cinellu et al described for the first time the synthesis and structural characterization of cationic tricoordinate gold(I) $\pi$-complexes using different substituted bipyridine ligands. ${ }^{65,66,67}$ Dicationic dinuclear gold(III) $\mu$, $\mu$-dioxo compounds were reduced by olefins and diolefins (Scheme 1) to give mononuclear gold(I) $\pi$-complexes of the type $[\mathrm{Au} \text { (bipy)(ene) }]^{+}$(23 examples) or dinuclear gold(I) complexes with a bridging diolefin (7 examples) in low to moderate yields. The $[\mathrm{Au} \text { (bipy)(ene) }]^{+}$complexes were found to be surprisingly stable thermally, with melting points above $100^{\circ} \mathrm{C}$. The olefins are bound sufficiently strongly to the gold(I) center not to dissociate either in solution or in solid state under vacuum. The olefin is not even replaced by common coordinating solvents such as acetonitrile or by CO at atmospheric pressure. However, addition of an excess of the corresponding olefin caused broadening of the ${ }^{1} \mathrm{H}$ NMR signals of the coordinated alkene, indicating fast intermolecular exchange between the coordinated and free olefin at room temperature. Variable temperature ${ }^{1} \mathrm{H}$ NMR spectroscopy showed that the dynamic process is frozen at low temperature (193 K), where the different olefinic proton signals are well-separated. In the majority of the complexes, the signals of the olefin protons are sharp and showed a significant high-field shift with respect to 
those of the free alkenes $\left(\Delta \delta^{1} \mathrm{H}\right.$ in the range of $\left.0.8-2.2 \mathrm{ppm}\right)$. Likewise, the ${ }^{13} \mathrm{C}$ NMR signals for the olefinic carbons are upfield shifted upon coordination $\left(\Delta \delta^{13} \mathrm{C}\right.$ in the range of $\left.47.5-61.7 \mathrm{ppm}\right)$. These spectroscopic values are in marked contrast with the minor changes observed upon coordination of olefins to gold(I) centers ligated to phosphines or NHCs. The solid-state structures of the $\left[\mathrm{Au}(\mathrm{bipy})\left(\eta^{2} \text {-styrene }\right)\right]^{+}$complexes $\mathbf{4}$ and $\mathbf{5}$ display trigonal planar environments around the gold atom (Figure 5). The olefin is coplanar with the pyridine backbone, which chelates the gold center with bite angles around $75^{\circ}$. The gold-carbon distances were found to be slightly shorter than in other gold(I)-alkene complexes. Most remarkable are the $\mathrm{C}-\mathrm{C}$ bond lengths of the coordinated olefin, which were elongated (>0.03 $\AA$ ) in comparison with the free olefin. All these data indicate that the chelating bipyridine ligand induces some metallacyclic character as the result of significant $\mathrm{Au} \rightarrow$ alkene backdonation. DFT calculations on the model cation $\left[\mathrm{Au}(\text { bipy })\left(\eta^{2}-\mathrm{CH}_{2}=\mathrm{CH}_{2}\right)\right]^{+}$were used to thoroughly analyze the $\mathrm{Au}(\mathrm{I})$-alkene bonding situation. Natural Bond Orbital (NBO) populations, Wiberg bond indexes (WBI) and Bond Dissociation Energies (BDE) all indicate significant $\mathrm{Au} \rightarrow$ alkene $\pi$ backdonation compared to $\sigma$ donation, in line with the spectroscopic and structural data.

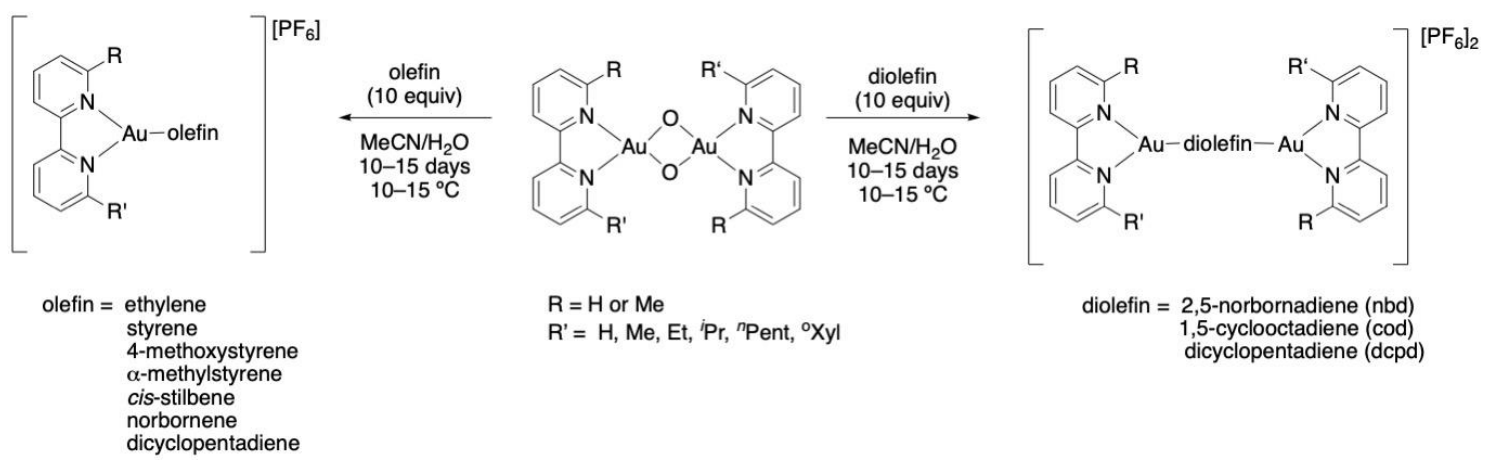

Scheme 1. Synthesis of the tricoordinate $[\mathrm{Au}(\mathrm{bipy})(\mathrm{ene})]^{+} \pi$-complexes and dinuclear gold(I) complexes with bridging diolefins [(bipy) $\mathrm{Au}(\text { diolefin) } \mathrm{Au}(\mathrm{bipy})]^{2+}$.
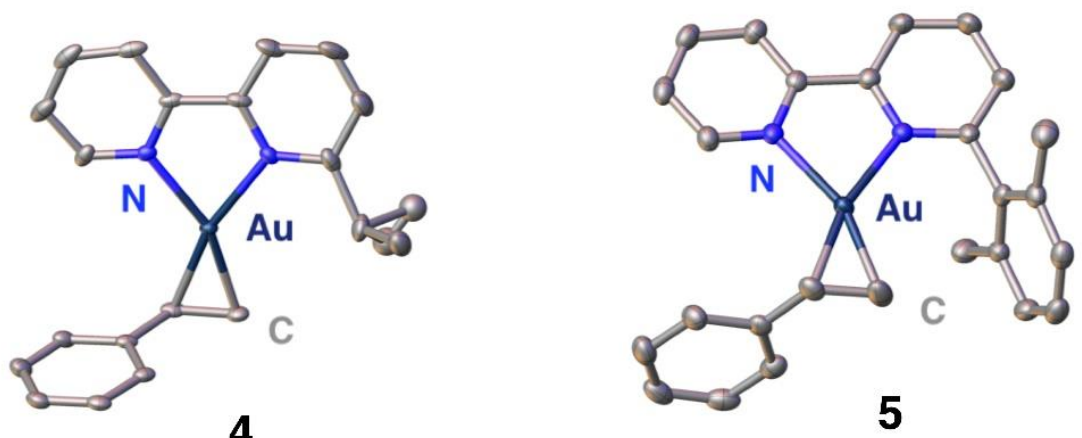

Figure 5. Molecular structure of the $\left[\mathrm{Au}(\text { bipy)(styrene) }]^{+}\right.$complexes $\mathbf{4}$ and $\mathbf{5}$. 
Gold-ethylene adducts are particularly rare ${ }^{68}$ See section 2.3 for a detailed comparison of the spectroscopic and structural data of the few known complexes discussed hereafter. In a pioneering work, Dias et al described in 2007 two singular neutral gold(I) ethylene complexes with monoanionic tris(pyrazolyl)borates as supporting ligands (Scheme 2). ${ }^{69,70,71}$ Reaction of the tris(pyrazolyl)borate sodium salt with gold(I) chloride under an ethylene atmosphere afforded complexes 6a,b as colorless stable solids in good yields (> 70\%). Remarkably, the ethylene molecule remained tightly bounded to gold(I) even when reduced pressure was applied. Also, in the presence of excess of ethylene, no alkene exchange was observed on the NMR time scale. As for the bipyridine gold(I) $\pi$-complexes, the ${ }^{1} \mathrm{H}$ and ${ }^{13} \mathrm{C}$ NMR signals for the coordinated ethylene are markedly shifted upfield in comparison with free ethylene (3.81 and $63.7 \mathrm{ppm}$ versus 5.43 and $116.8 \mathrm{ppm}$, respectively). However, there are no noticeable differences in chemical shifts between this neutral gold(I) ethylene complex and the related cationic gold(I) ethylene complexes, suggesting that the nature of the supporting ligand does not considerably affect the gold(I)-ethylene ligation. The single-crystal X-ray diffraction analysis showed a gold atom with trigonal-planar coordination geometry. The ethylene molecule sits in the coordination plane of the metal. It is bonded in a typical $\eta^{2}$-fashion with $\mathrm{Au}-\mathrm{C}$ bond lengths of 2.096(6) and 2.108(6) $\AA$. The $\mathrm{C}=\mathrm{C}$ bond $(1.380(10) \AA)$ is longer than that of free ethylene $(1.313 \AA) .{ }^{72,73}$ These bond distances are similar to those found in the cationic gold(I) ethylene complexes bearing bipyridine ligands (see below). The tris(pyrazolyl)borate ligand coordinates to gold in a $\kappa^{2}$-fashion with $\mathrm{Au}-$ $\mathrm{N}$ distances of 2.2221(5) and 2.224(5) $\AA$, while the unbounded nitrogen of the third pyrazolyl moiety is $2.710 \AA$ away (which remains within the sum of van der Waals radii of Au and N). ${ }^{74}$ However, complex 6a showed fluxional behavior in solution even at $-80{ }^{\circ} \mathrm{C}$, with no differentiated signals for the coordinated and free pyrazolyl moieties in ${ }^{1} \mathrm{H}$ and ${ }^{19} \mathrm{~F}$ NMR spectroscopy suggesting fast exchange between the pendant and coordinated sidearms. Analogous complexes supported by electron-rich scorpionates $\left(\mathrm{R}, \mathrm{R}^{\prime}=\mathrm{Ph}, t \mathrm{Bu}\right) \mathbf{7 a}, \mathbf{b}$ were recently prepared. ${ }^{75} \mathrm{NMR}$, crystallographic and computational data are indicative of enhanced $\mathrm{Au} \rightarrow$ ethylene backdonation.

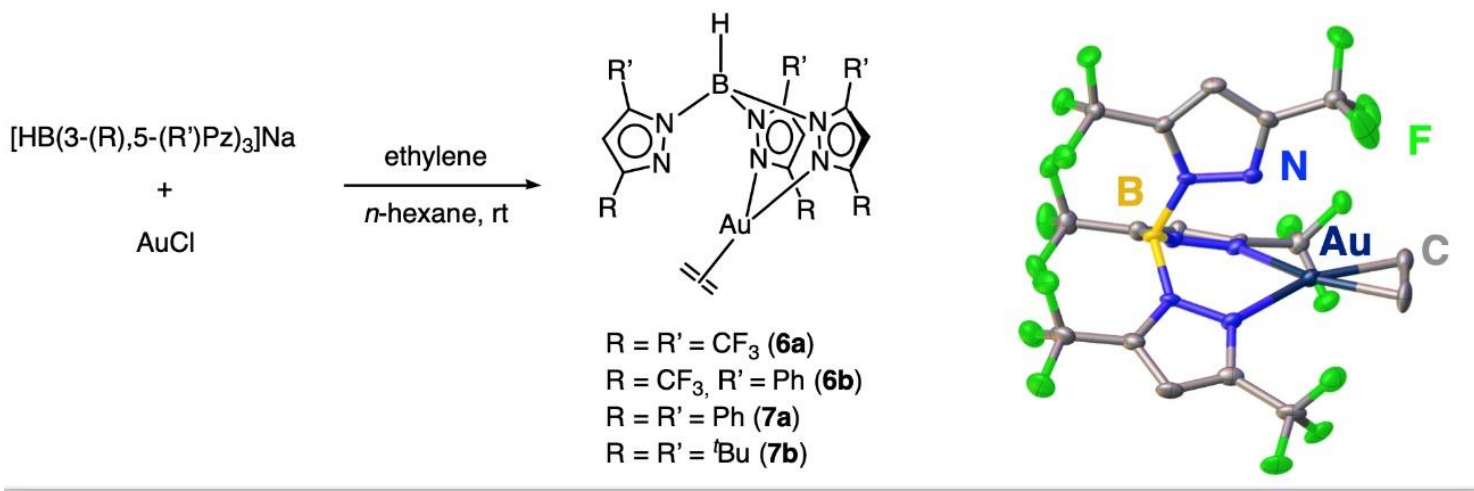

Scheme 2. Synthesis and structure of the tris(pyrazolyl)borate gold(I) ethylene complexes 6 and 7. 
In a subsequent study, the same research group capitalized on the chelating nature of triazapentadienyl ligands to stabilize a gold(I)-ethylene complex. ${ }^{76}$ Treatment of the triazapentadienyl lithium salt with gold(I) chloride in the presence of ethylene led to the formation of the neutral gold(I)-ethylene complex $\mathbf{8}$ as a yellow solid (Scheme 3A). The ${ }^{1} \mathrm{H}$ NMR signal corresponding to the ethylene protons appeared as a singlet at $2.71 \mathrm{ppm}$. The upfield shift with respect to free ethylene is larger than that observed for related gold(I)-ethylene complexes, which is most likely due to the ring current effect caused by the aryl group rings of the ligand flanking the ethylene moiety. The ${ }^{13} \mathrm{C}$ NMR signal of the coordinated ethylene appears at $59.1 \mathrm{ppm}$, in line with the other reported cationic and neutral gold(I)-ethylene complexes. The X-ray structure of complex 8 displays a trigonal-planar coordination geometry, with the triazapentadienyl ligand binding the metal center in a $\kappa^{2}$ fashion and with the ethylene molecule sitting in the plane of the $\mathrm{N}^{\wedge} \mathrm{N}-\mathrm{Au}(\mathrm{I})$ fragment. In this case, the $\mathrm{C}=\mathrm{C}$ bond length of the coordinated ethylene is also longer (1.405(4) $\AA$ ) than that of free ethylene. Of note, this $\mathrm{Au}(\mathrm{I})$-ethylene complex 8 was proved to efficiently mediate carbene-transfer reactions from ethyl diazoacetate to saturated and unsaturated hydrocarbons ( $\mathrm{C}-\mathrm{H}$ insertion, cyclopropanation reactions).

A similar ligand scaffold was used to prepare the first tricoordinated gold(I) alkyne complex following the same synthetic procedure. ${ }^{77}$ Treatment of $\mathrm{AuCl}$ with $\left[\mathrm{N}\left\{\left(\mathrm{C}_{3} \mathrm{~F}_{7}\right) \mathrm{C}(\mathrm{Dipp}) \mathrm{N}\right\}_{2}\right] \mathrm{Li}$ (prepared directly from $\left[\mathrm{N}\left\{\left(\mathrm{C}_{3} \mathrm{~F}_{7}\right) \mathrm{C}(\mathrm{Dipp}) \mathrm{N}\right\}_{2}\right] \mathrm{H}$ and $n \mathrm{BuLi}$ ) in the presence of 3-hexyne in hexane afforded the $\left(\mathrm{N}^{\wedge} \mathrm{N}\right) \mathrm{Au}(\mathrm{EtC} \equiv \mathrm{CEt})$ complex 9 as a yellow solid in $85 \%$ yield (Scheme $\left.3 \mathrm{~B}\right)$. This $\mathrm{Au}(\mathrm{I})$-alkyne complex was remarkably stable and could be handled in air without decomposition. The ${ }^{1} \mathrm{H}$ NMR spectrum exhibits signals corresponding to the ethyl moieties of the alkyne at the 1.1-0.75 ppm region, which is an upfield shift compared to the corresponding signals of free 3-hexyne (2.13 and $1.09 \mathrm{ppm}$ ). This shift is likely due to the ring currents of the flanking $\mathrm{N}$-aryl groups, rather than a direct electronic implication of the $\mathrm{Au}-$ alkyne bond. The ${ }^{13} \mathrm{C} \mathrm{NMR}$ signal of the acetylenic carbons appeared at $91.3 \mathrm{ppm}$, which is relatively downfield shifted in comparison with free 3-hexyne (80.9 ppm), and very similar to dicoordinate gold(I)-alkyne complexes. $^{78,79,80,81}$ The X-ray structure of complex 9 presents a tricoordinate gold(I) center. The triazapentadienyl ligand coordinates the gold center in a $\kappa^{2}$ fashion with a $\mathrm{N}-\mathrm{Au}-\mathrm{N}$ bite angle of $85.31(13)^{\circ}$. The coordinated 3-hexyne sits in the plane of the $\left[\left(\mathrm{N}^{\wedge} \mathrm{N}\right) \mathrm{Au}\right]^{+}$fragment. In this case, the $\mathrm{C} \equiv \mathrm{C}$ bond length is marginally longer (1.233(7) $\AA$ ) than that computed for free 3-hexyne $(1.215 \AA)$. According to DFT calculations, the enthalpy of formation of the model $\pi$-complex $\left[\mathrm{N}\left\{\left(\mathrm{CF}_{3}\right) \mathrm{C}\left(\mathrm{C}_{6} \mathrm{H}_{5}\right) \mathrm{N}\right\}_{2}\right] \mathrm{M}(\mathrm{EtC} \equiv \mathrm{CEt})$ is $36.6 \mathrm{kcal} / \mathrm{mol}$. NBO analysis showed that $\sigma$-donation from the alkyne to the metal center dominates over $\mathrm{Au} \rightarrow$ alkyne $\pi$-backdonation (109.8 versus 48.1 $\mathrm{kcal} / \mathrm{mol}$ ). In addition, the coordination of the alkyne was found to be stronger for gold than copper and silver, as well as the degree of backdonation versus donation. 
A)
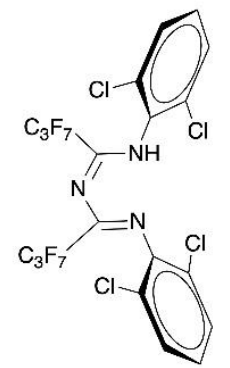

2) $\mathrm{AuCl}, \mathrm{C}_{2} \mathrm{H}_{4}$

$\mathrm{Et}_{2} \mathrm{O}$

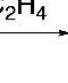

B)

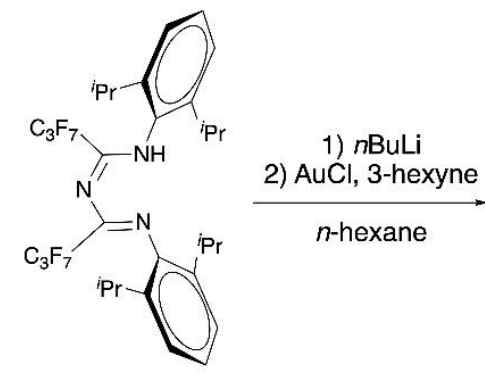

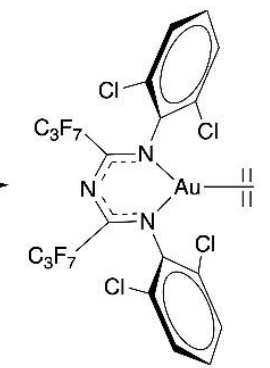

8

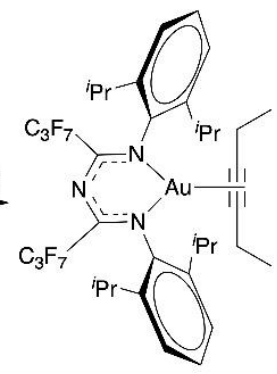

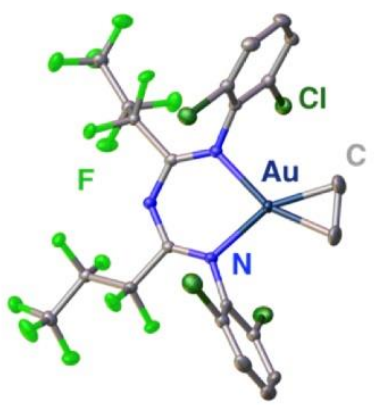

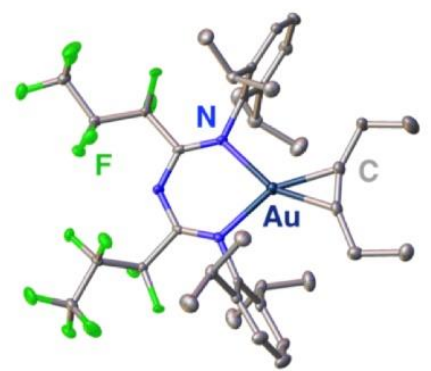

Scheme 3. Synthesis and structure of the triazapentadienyl gold(I) ethylene and 3-hexyne complexes 8 and 9.

A few cationic $\mathrm{Au}(\mathrm{I})$-ethylene complexes have also been described. In 2016, Daugulis et al reported a stable complex featuring an hindered $\alpha$-diimine ligand..$^{82}$ Reaction of tris(ethylene)gold hexafluoroantimonate $\mathbf{1 0}^{83}$ and the diimine ligand under ethylene atmosphere afforded the tricoordinate gold(I)-ethylene complex 11 in moderate yields (42\%) (Scheme 4). Complex 11 decomposed in solution within an hour at room temperature and had to be handled under inert atmosphere. Both ${ }^{1} \mathrm{H}$ and ${ }^{13} \mathrm{C}$ NMR signals corresponding to the ethylene moiety are upfield shifted in comparison with the free olefin (3.31 and 3.28 versus 5.43 ppm and 65.4 versus 116.8 ppm, respectively). Olefin exchange in presence of excess ethylene was found to occur, albeit slowly on the NMR time scale even at $50^{\circ} \mathrm{C}$. To determine the exchange rate, complex 11-d 4 was prepared in good yield (81\%) by purging a solution of complex 11 with $\mathrm{C}_{2} \mathrm{D}_{4}$. Treatment with an excess of $\mathrm{C}_{2} \mathrm{H}_{4}$ was then monitored by ${ }^{1} \mathrm{H}$ NMR spectroscopy giving $\Delta \mathrm{G}_{298}{ }^{\ddagger}=12.9 \pm 0.1 \mathrm{kcal} / \mathrm{mol}$, $\Delta \mathrm{H}^{\ddagger}=10.0 \pm 1.4 \mathrm{kcal} / \mathrm{mol}$ and $\Delta \mathrm{S}^{\ddagger}=-22.5 \pm 4.8 \mathrm{eu}$, consistent with an associative exchange mechanism. The complex displayed a tri-coordinate $\mathrm{Au}(\mathrm{I})$ center with the metal, the diimine ligand and the ethylene molecule lying in the same plane. The $\mathrm{C}=\mathrm{C}$ bond of the $\eta^{2}$-coordinated ethylene molecule $(1.455(13) \AA)$ is longer than those observed in structurally characterized dicoordinate $\mathrm{Au}(\mathrm{I})$-ethylene complexes (1.35-1.39 $\AA$ ). 

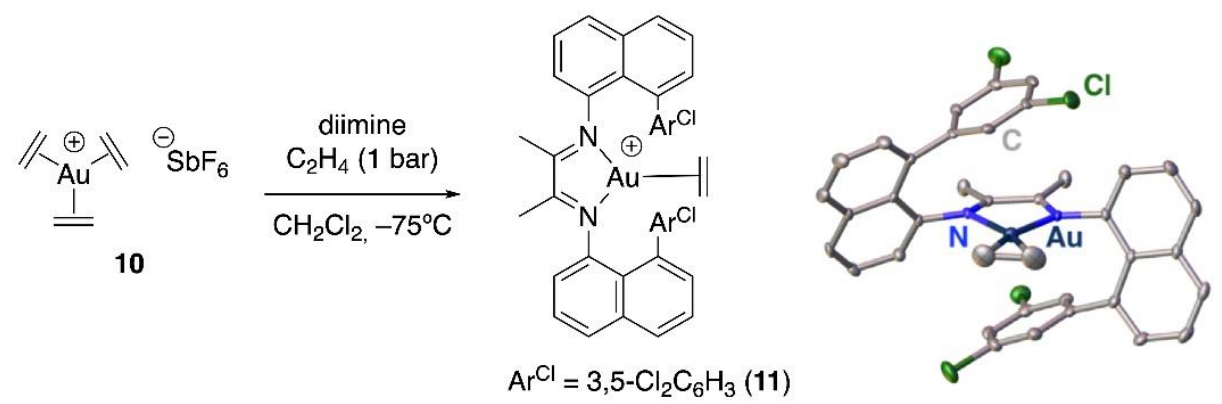

Scheme 4. Synthesis and structure of the $[\mathrm{Au}($ diimine)(ethylene)][SbF 6$]$ complex 11.

In 2018, the group of Russell used the synthetic methodology developed by Daugulis et al to prepare cationic $[\mathrm{Au} \text { (bipy)(ene) }]^{+}$complexes. ${ }^{84}$ The reaction of 2,2'-bipyridines with the unstable gold(I) tris-ethylene complex $\left[\mathrm{Au}\left(\mathrm{C}_{2} \mathrm{H}_{4}\right)_{3}\right]\left[\mathrm{NTf}_{2}\right]$ afforded [ $\mathrm{Au}($ bipy $\left.)\left(\mathrm{C}_{2} \mathrm{H}_{4}\right)\right]\left[\mathrm{NTf}_{2}\right]$ complexes $\mathbf{1 2}$ and 13 in good yields ( $\sim 00 \%$ ) (Scheme 5). These complexes showed impressive stability. They can be handled in air and used for subsequent reactions in non-anhydrous solvents (for oxidative addition of $\mathrm{C}\left(\mathrm{sp}^{2}\right)-\mathrm{I}$ and $\mathrm{C}(\mathrm{sp})-\mathrm{I}$ bonds in particular). ${ }^{84,85}$ The molecular structure of the complex 13 revealed a distorted trigonal planar gold center with the bipyridine and ethylene ligands in the same plane and symmetrically $\kappa^{2} / \eta^{2}$ coordinated. Analogous to the [Au(bipy)(styrene) $]^{+}$ complexes previously described by Cinellu et al, the $\mathrm{Au}-\mathrm{C}$ bond distances are contracted and the $\mathrm{C}=\mathrm{C}$ bond is significantly elongated compared to the two-coordinate $[\mathrm{Au}(\mathrm{L})(\mathrm{ene})]^{+}$complexes $(\mathrm{L}$ $=\mathrm{PR}_{3}$ or NHC). The ${ }^{1} \mathrm{H}$ and ${ }^{13} \mathrm{C}$ NMR signals for the coordinated ethylene are both remarkably upfield shifted in comparison with free ethylene (ie. 3.90 and 63.8 versus 5.43 and 116.8 ppm respectively). Again, this is the result of enhanced $\pi$-backdonation induced by the chelating bipyridine ligand. 

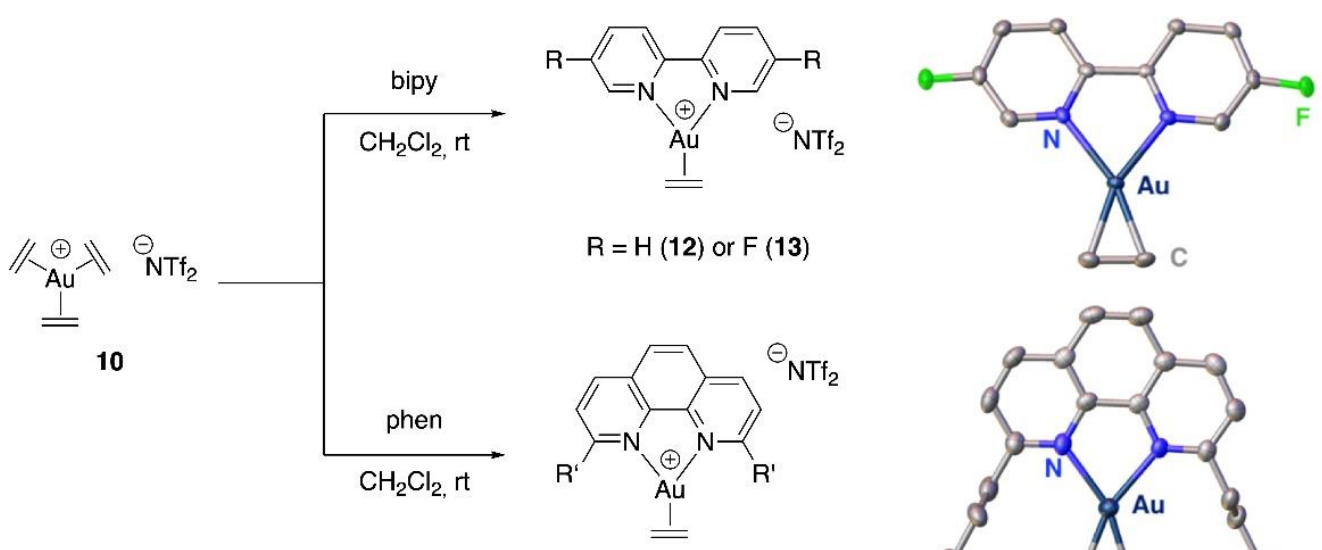

$\mathrm{R}^{\prime}=\mathrm{H}(14)$ or $\mathrm{nBu}(\mathbf{1 5})$

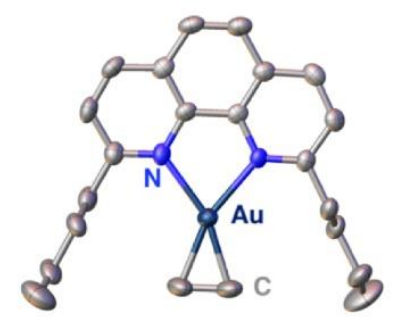

Scheme 5. Syntheses and structures of the gold(I)-ethylene bipyridine and phenanthroline complexes reported by the Russell's and Hashmi's groups.

Different studies by Shi, Liu and Waser et al on gold-catalyzed alkynylations have shown that $\mathrm{Au}(\mathrm{I})$ complexes can catalyze alkynylation reactions. ${ }^{86,87,88,89,90,91}$ The alkynylation product likely results from reductive elimination of an alkynyl Au(III) complex, which is derived from oxidative addition of an alkynyl iodonium salt to gold(I). In order to gain more insight into this catalytic transformation, the group of Hashmi synthetized in 2019 [(Phen) $\left.\mathrm{Au}\left(\mathrm{C}_{2} \mathrm{H}_{4}\right)\right][\mathrm{NTf}]_{2}$ complexes 14 and 15 (Scheme 5) following the same synthetic procedure than that used by Daugulis and Russell. ${ }^{92}$ Complex 15 proved to be a competent pre-catalyst for the alkynylation of cyclopropenes. As for the bipyridine analogues, ${ }^{1} \mathrm{H}$ and ${ }^{13} \mathrm{C}$ NMR spectroscopy showed a marked upfield shift of the ethylene signals. In addition, the $\mathrm{C}=\mathrm{C}$ bond distance (1.411(10) $\AA$ ) is larger than in dicoordinate gold(I)-ethylene complexes. Note that the phenanthroline ligand is coordinated in a symmetric $\kappa^{2}$ fashion, in marked contrast with that found in related (Phen)Au(phosphine) $)^{+}$complexes. ${ }^{93}$

In a recent study, Pintus, Maiore et al have also utilized phenanthrolines as $\mathrm{N}^{\wedge} \mathrm{N}$-chelating ligands to prepare a series of stable tricoordinate $\mathrm{Au}(\mathrm{I}) \pi$-complexes with norbornene as alkene (6 examples). ${ }^{94}$ In a first attempt, $[\mathrm{Au}(\mathrm{phen})(\mathrm{nb})]^{+}$-type complexes $(\mathrm{nb}=$ norbornene) were synthetized from the dimeric $\mathrm{Au}(\mathrm{III})$-oxo species following the synthetic procedure described by Cinellu et al. The desired products were obtained in low yields and after long reaction times ( $>10$ days) (Scheme 6, route A). As observed in the (di)substituted 2,2'-bipyridine derivatives, ${ }^{65,66}$ a mixture of the gold $(\mathrm{I})$ alkene $[\mathrm{Au}(\mathrm{phen})(\mathrm{nb})]\left[\mathrm{PF}_{6}\right]$ complexes and the aura-oxetane $\left[\mathrm{Au}\left(\kappa^{2}-O, C\right.\right.$ 2-oxynorbornyl)(NCP)][$\left[\mathrm{PF}_{6}\right]$ was obtained. Although the molar ratio of the two complexes could 
be optimized, separation of the mixture required tedious work-up. A cleaner and more effective synthetic route was thus developed. The $[\mathrm{Au}(\mathrm{phen})(\mathrm{nb})]\left[\mathrm{PF}_{6}\right]$ complexes 16 were obtained in higher yields (up to $80 \%$ ) and very short reaction times ( $<40 \mathrm{~min}$ ) by reacting the phenanthroline ligand with $[\mathrm{Au}(\mathrm{tht}) \mathrm{Cl}]$ in dichloromethane, followed by the addition of $\mathrm{AgPF}_{6}$ and norbornene (Scheme 6, route B).

A)
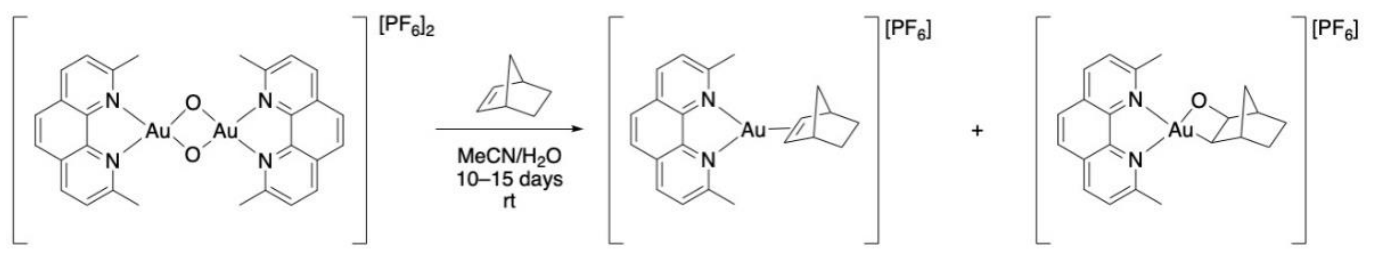

B)
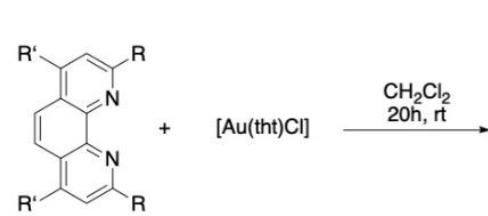

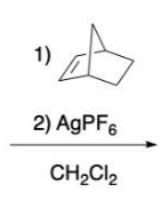

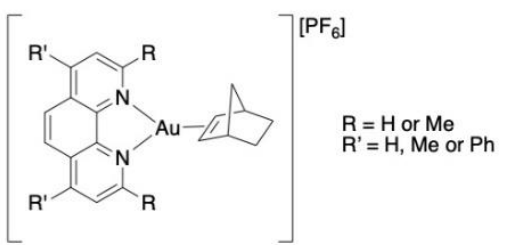

16

Scheme 6. Synthesis of $[\mathrm{Au}(\mathrm{phen})(\mathrm{nb})]\left[\mathrm{PF}_{6}\right]$ complexes by reduction of the $\mathrm{Au}(\mathrm{III})$ dioxo complexes (A) and directly by halogen abstraction and olefin coordination (B).

The $[\mathrm{Au}(\mathrm{phen})(\mathrm{nb})]\left[\mathrm{PF}_{6}\right]$ complexes $\mathbf{1 6}$ are stable both in solution and in the solid state showing no sign of olefin dissociation or degradation. In the ${ }^{1} \mathrm{H}$ NMR spectrum, the olefin protons are significantly high-field shifted with respect to those of free norbornene, in accordance with significant $\pi$-backdonation enforced by the chelating nature of the ligand, with $\Delta \delta^{1} \mathrm{H}$ up to 1.70 ppm, while the other aliphatic protons remain almost unchanged or resonate at lower field. Likewise, the resonance of the olefin $\mathrm{C}=\mathrm{C}$ carbon atoms are shifted upfield $\left(\Delta \delta^{13} \mathrm{C}\right.$ up to 53.3 $\mathrm{ppm})$. According to XRD analyses, all the complexes display tri-coordinate $\mathrm{Au}(\mathrm{I})$ centers with the $\mathrm{C}=\mathrm{C}$ bond of the norbornene ligand lying in the plane of the $\mathrm{Au}\left(\mathrm{N}^{\wedge} \mathrm{N}\right)$ fragment (Figure 6). The $\mathrm{C}=\mathrm{C}$ distances are elongated with respect to the free alkene, in agreement with $\pi$ backdonation from the metal center. DFT calculations confirmed the bonding features, and further elucidated the nature of the molecular orbitals involved. NBO analysis indicated that $\sigma$-donation prevails over $\pi$-backdonation. While $\pi$-backdonation is practically the same for all the complexes, the $\sigma$-donation is directly related with the nature of the substituents of the phenanthroline ligands, being weaker for phenanthroline ligands featuring substituents in the position $\alpha$ to $\mathrm{N}$, possibly due to their steric hindrance. 

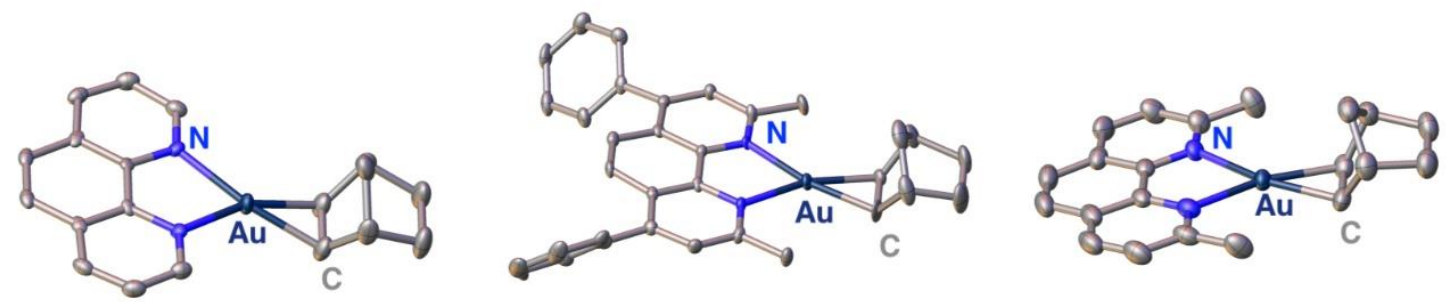

Figure 6. Some molecular structures of phenanthroline gold(I) norbornene complexes 16.

\subsection{Gold(I) $\pi$-complexes with $P^{\wedge} P$ and $P^{\wedge} N$-chelating ligands}

Bidentate P-donor ligands have been less studied in gold(I) chemistry. In this respect, our group has been interested in $o$-carboranyl-bridged diphosphines $\left(o\right.$-CBD) and $o$-phenylene-bridged $\mathrm{P}^{\wedge} \mathrm{N}$ ligands. Both ligands are chelating and enforce unusual bent geometry at gold(I), which enables oxidative addition of $\mathrm{C}-\mathrm{X}$ and $\mathrm{C}-\mathrm{C}$ bonds to gold under mild conditions. ${ }^{10,11,12}$ The hemilabile character of the $\mathrm{P}^{\wedge} \mathrm{N}$ ligand was shown to promote $\mathrm{Au}(\mathrm{I}) / \mathrm{Au}(\mathrm{III})$ catalysis. ${ }^{12,15,16,17,18,19,20,21}$ In addition, in recent parallel studies, our group and Patil's group have highlighted the role of tricoordinate gold(I) alkene complexes in catalytic arylation reactions merging oxidative addition and $\pi$-activation at gold. ${ }^{17,19,20}$ Coordination of the alkene to the gold(I) center was found to occur prior the oxidative addition step, but without preventing it to take place (Scheme 7).

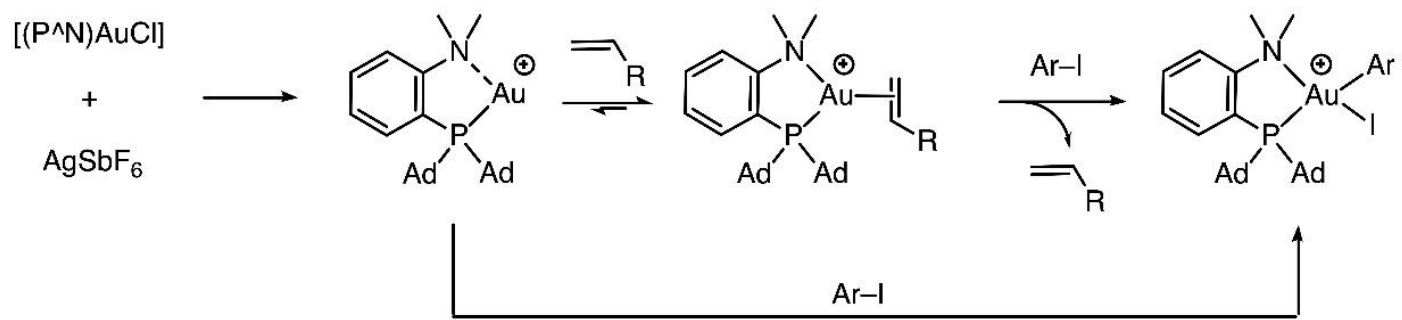

Scheme 7. Proposed mechanism of oxidative addition to gold of aryl iodides with and without the presence of alkenes.

Reaction of the $o$-carboranyl diphosphine gold(I) chloride with $\mathrm{AgSbF}_{6}$ in the presence of an excess of styrene or ethylene in dichloromethane afforded the $\left(\mathrm{P}^{\wedge} \mathrm{P}\right) \mathrm{Au}(\mathrm{I}) \pi$-complexes $\mathbf{1 7}$ and $\mathbf{1 8}$ in good yields (Scheme 8 ) ${ }^{95,96}$ Both complexes are air stable solids. The alkene is tightly bonded to the gold(I) center, with no chemical exchange between coordinated and free alkene at the NMR time-scale. In addition, no sign of styrene or ethylene decoordination was observed under vacuum. 
Coordination of styrene to gold induced noticeable upfield shifts of the ${ }^{1} \mathrm{H}(4.75,4.33$ and 4.25 $\mathrm{ppm})$ and ${ }^{13} \mathrm{C}$ NMR (65.9 and $95.0 \mathrm{ppm}$ ) vinylic signals with respect to free styrene $(5.74,5.24$ and $6.72 \mathrm{ppm} ; 113.7$ and $136.9 \mathrm{ppm}$ respectively). The same spectroscopic behavior was seen upon ethylene coordination. In both complexes, the $o$-CBD ligand is symmetrically coordinated to gold and the $\mathrm{P}-\mathrm{Au}-\mathrm{P}$ bite angle $\left(89.13(3)^{\circ}\right.$ and $\left.91.32(7)^{\circ}\right)$ is similar to those previously observed in $\left[\left(\mathrm{P}^{\wedge} \mathrm{P}\right) \mathrm{Au}(\mathrm{CO})\right]^{+}$and $\left[\left(\mathrm{P}^{\wedge} \mathrm{P}\right) \mathrm{Au}=\mathrm{C}(\mathrm{Ph}) \mathrm{R}\right]^{+}$complexes (see section 3). ${ }^{97,98}$ In both complexes, the gold center is in a trigonal planar environment, and the alkene coordinates in the same plane as the $\mathrm{P}^{\wedge} \mathrm{P}$ ligand. This arrangement maximizes the overlap between the HOMO of the $\left[\left(\mathrm{P}^{\wedge} \mathrm{P}\right) \mathrm{Au}\right]^{+}$fragment (in-plane $\mathrm{d}_{\mathrm{xy}}$-type orbital) and the $\pi^{*}$ orbital of the alkene enforcing substantial $\mathrm{Au} \rightarrow$ alkene backdonation, as for the related $\mathrm{N}^{\wedge} \mathrm{N}$ chelating ligands. This $\pi$ backdonation is further noticed in the metrical parameters for the styrene and ethylene molecules coordinated to gold. The $\mathrm{C}=\mathrm{C}$ bonds (1.395(4) $\AA$ and 1.365(15) $\AA$ ) are elongated in comparison to free styrene and ethylene ( $1.35 \AA$ and $1.313 \AA$ ).
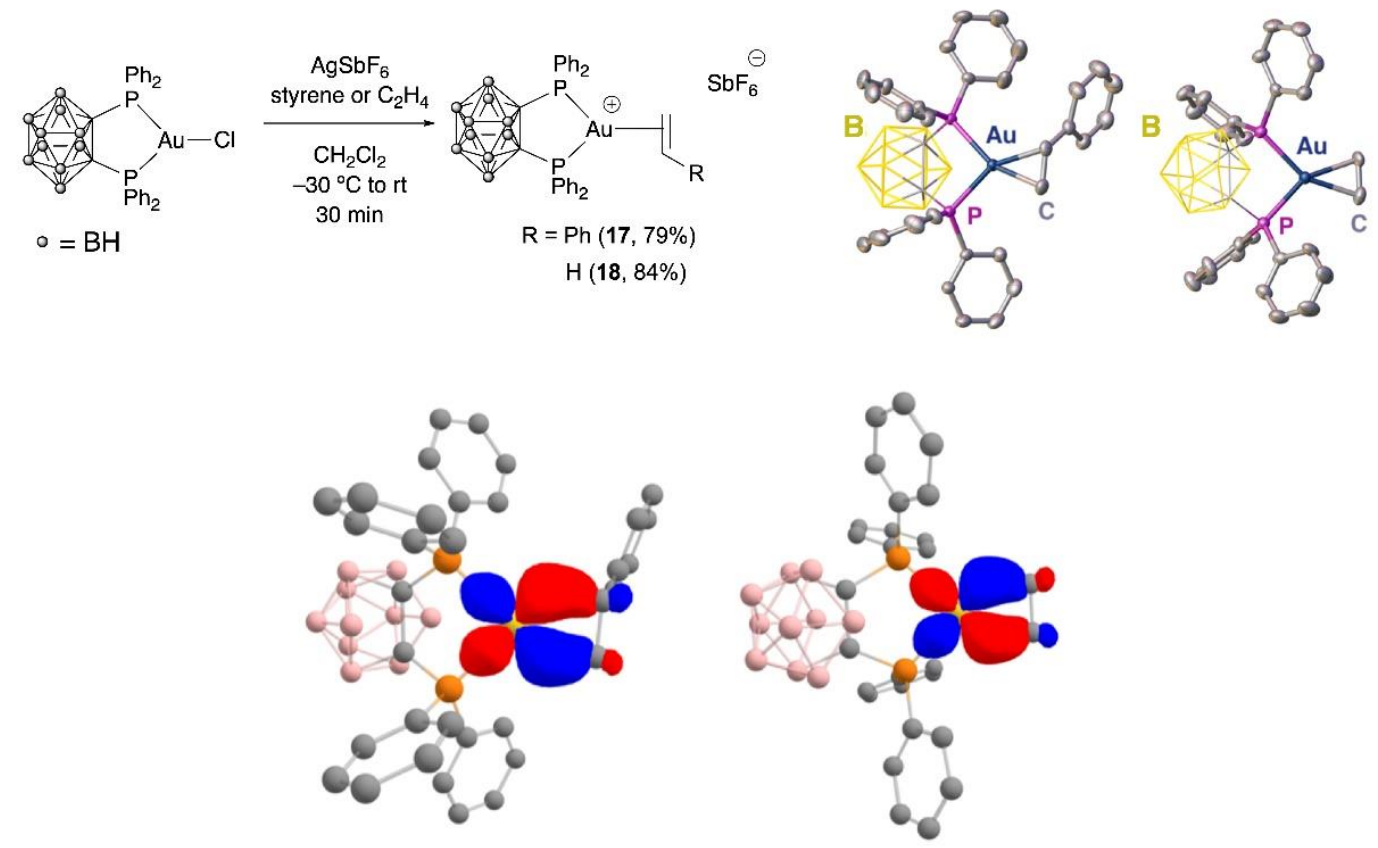

Scheme 8. Synthesis, molecular structures and plots of the NLMO associated to $\mathrm{d}(\mathrm{Au}) \rightarrow \pi^{*}(\mathrm{C}=\mathrm{C})$ backdonation of $o$-carboranyl diphosphine gold(I) styrene (17) and ethylene (18) complexes.

The gold(I) complex deriving from the $\mathrm{P}^{\wedge} \mathrm{N}$ hemilabile ligand MeDalphos has also shown interesting features towards different alkenes. ${ }^{95,96}$ Reaction of MeDalphos gold(I) chloride with unbiased alkenes and alkynes such as styrene, ethylene, 1-hexene and 3-hexyne in the presence of $\mathrm{AgSbF}_{6}$ afforded the corresponding gold(I) $\pi$-complexes 19-22 (Scheme 9). The ${ }^{1} \mathrm{H}$ NMR spectra display new sets of well-defined vinylic signals (distinct from those of the free $\pi$ - 
compounds), indicating the coordination of the alkene to gold. Also noteworthy is the presence of two distinct downfield shifted ${ }^{1} \mathrm{H}$ NMR singlets at $\sim 3 \mathrm{ppm}$ for complexes 19 (styrene) and 21 (1-hexene) for the $\mathrm{N}\left(\mathrm{CH}_{3}\right)_{2}$ group, in comparison with one singlet at $2.57 \mathrm{ppm}$ for the starting $\left[\left(\mathrm{P}^{\wedge} \mathrm{N}\right) \mathrm{AuCl}\right]$ complex. This splitting and the downfield shift indicate that the nitrogen atom coordinates to the $\mathrm{Au}(\mathrm{I})$ center. On the other hand and due to the symmetric nature of the ethylene and 3-hexyne, the $\mathrm{N}\left(\mathrm{CH}_{3}\right)_{2}$ group displayed in complexes $\mathbf{2 0}$ and $\mathbf{2 2}$ only one singlet at $\sim 3 \mathrm{ppm}$, which is downfield shifted in comparison with the $\left[\left(\mathrm{P}^{\wedge} \mathrm{N}\right) \mathrm{AuCl}\right]$ complex, suggesting here also $\mathrm{N}$-coordination to gold(I). In addition, all complexes showed great stability towards air and no sign of alkene/alkyne exchange in the presence of excess of alkene/alkyne at the NMR time-scale or dissociation under vacuum. Coordination to gold(I) induced a marked upfield shift of the ${ }^{1} \mathrm{H}$ and ${ }^{13} \mathrm{C}$ NMR signals with respect to the free alkene/alkyne. These shift differences reached up to $2.13 \mathrm{ppm}$ in ${ }^{1} \mathrm{H}$ NMR and $65 \mathrm{ppm}$ in ${ }^{13} \mathrm{C}$ NMR spectroscopy, suggesting substantial gold $\rightarrow$ alkene backdonation. The complexes 19 and 20 adopted similar structures in the solid state with the $\mathrm{P}^{\wedge} \mathrm{N}$ ligand chelating gold (Figure 7). In both complexes, the gold center sits in a trigonal planar environment and the alkene lies in the $\left(\mathrm{P}^{\wedge} \mathrm{N}\right) \mathrm{Au}$ coordination plane. The presence of substantial $\mathrm{d}(\mathrm{Au}) \rightarrow \pi^{*}(\mathrm{C}=\mathrm{C})$ backdonation is apparent from the elongation of the $\mathrm{C}=\mathrm{C}$ bond upon coordination (by $\sim 0.06 \AA$ compared to the free alkene). The alkene is $\eta^{2}$-coordinated to gold, and both complexes presented quasi-symmetric structures with almost identical $\mathrm{Au}-\mathrm{C}$ bond lengths.

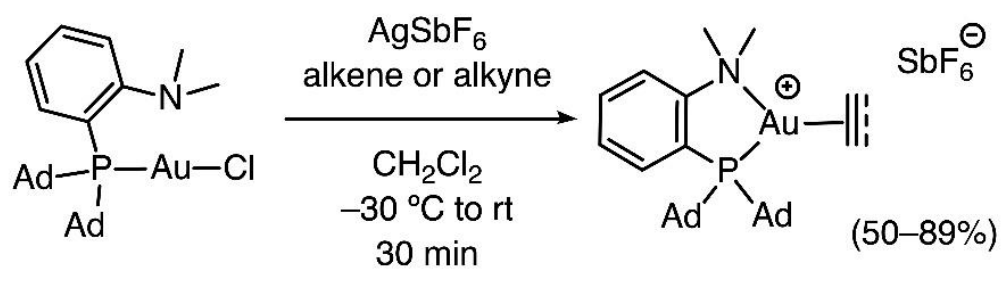<smiles>CN1c2ccccc2P(Cl)(=[Ge])[C@H]1/C=C/Pc1ccccc1</smiles>

19<smiles>CN1[GeH2]P(Cl)(Cl)(C2CCCCO2)c2ccccc21</smiles>

23

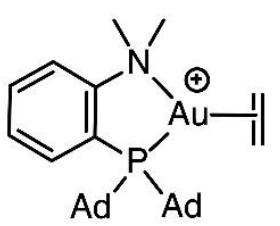

20<smiles>CCCC=C[Ge]1(C=CCCCC)N(C)c2ccccc2[PH]1(Cl)Cl</smiles>

21

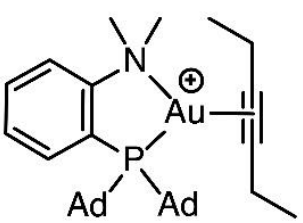

22<smiles>C=C(CC(C)=O)[Ge]1N(C)c2ccccc2[Ge]1(Cl)Cl</smiles>

24<smiles>CN1c2ccccc2P(Cl)(=C2C=CC(=O)N2c2ccccc2)[Ge]1(C)[Ge]</smiles>

25

Scheme 9. Synthesis of MeDalphos gold(I) $\pi$-complexes. 
In contrast to $\mathrm{N}^{\wedge} \mathrm{N}$ (bipyridines, phenanthrolines...) and $\mathrm{P}^{\wedge} \mathrm{P}(o-\mathrm{CBD})$ ligands, the hemilabile MeDalphos was found to be able to form stable $\pi$-complexes not only with unbiased alkenes but also with both electron-rich and electron-poor alkenes. Following the same synthetic procedure, MeDalphos gold(I) chloride reacted with 3,4-dihydro-2H-pyrane (DHP), methyl acrylate (MA) and $N$-phenylmaleimide (NPM) in the presence of $\mathrm{AgSbF}_{6}$ to yield the corresponding gold(I) $\pi$ complexes 23-25 (Scheme 9). The DHP and MA complexes 23 and 24 showed great stability, but the NPM complex 25 could not be isolated. Since decomposition occurred upon filtration, characterization was performed in the presence of $N$-phenylmaleimide without further purification. For the electron-poor MA and NPM containing complexes, ${ }^{1} \mathrm{H}$ and ${ }^{13} \mathrm{C}$ NMR spectroscopy revealed similar features to those with unbiased alkenes. The coordinated alkene signals are upfield shifted in comparison with the free alkene. In contrast, the coordination of DHP to gold was accompanied by a downfield shift of the vinylic signals.
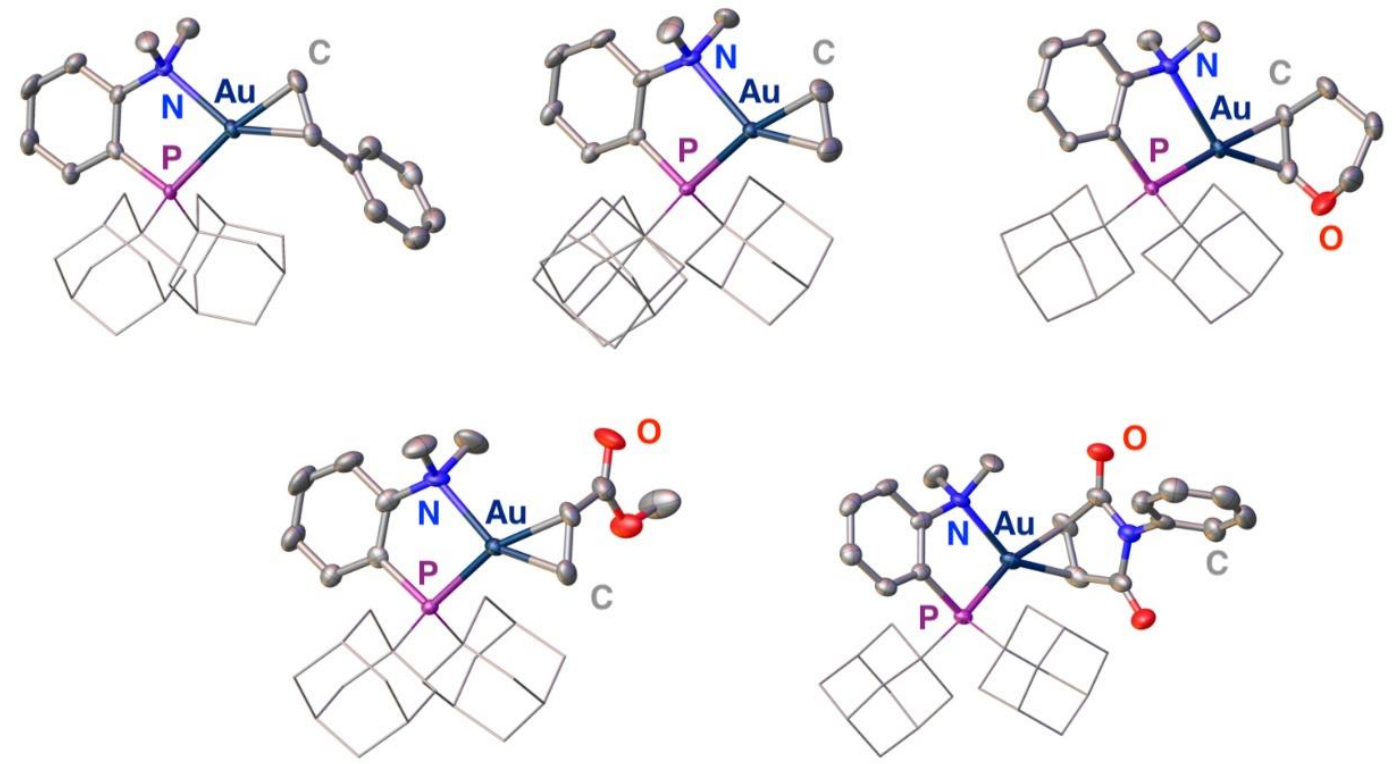

Figure 7. Molecular structures of the $\left[\left(\mathrm{P}^{\wedge} \mathrm{N}\right) \mathrm{Au}(\mathrm{ene})\right]^{+}$complexes.

Interestingly, the magnitude of the ${ }^{1} \mathrm{H}$ NMR downfield shift of the $\mathrm{N}\left(\mathrm{CH}_{3}\right)_{2}$ signal perfectly correlated with the electronic properties of the $\pi$-system: $\Delta \delta$ increases from $0.15 \mathrm{ppm}$ for the DHP complex (electron-rich alkene) to $0.82 \mathrm{ppm}$ for the NPM complex (electron-poor alkene), while complexes with unbiased alkenes exhibited intermediate values (Table 1). The same trends were observed in ${ }^{13} \mathrm{C}$ and ${ }^{31} \mathrm{P}$ NMR spectroscopy, suggesting that the $\mathrm{P}^{\wedge} \mathrm{N}$ ligand adjusts its coordination to gold depending on the electronics of the $\pi$-system. 
Table 1. Selected ${ }^{1} \mathrm{H},{ }^{13} \mathrm{C}$ and ${ }^{31} \mathrm{P}$ NMR data for the $\left(\mathrm{P}^{\wedge} \mathrm{N}\right) \mathrm{Au}(\mathrm{I}) \pi$-complexes 19-25.

\begin{tabular}{|c|c|c|c|c|c|c|c|c|c|c|}
\hline \multirow{2}{*}{$\left.{ }_{1}^{\mathrm{H}_{b}}{ }_{2}\right|_{\mathrm{R}} ^{\mathrm{H}_{\mathrm{a}}}$} & \multicolumn{5}{|c|}{$\delta^{1} \mathrm{H}(\mathrm{ppm})$} & \multicolumn{4}{|c|}{$\delta^{13} \mathrm{C}(\mathrm{ppm})$} & \multirow{2}{*}{$\begin{array}{c}\delta^{31} \mathrm{P} \\
(\mathrm{ppm})\end{array}$} \\
\hline & $\mathrm{H}_{1 \mathrm{a}}$ & $\mathrm{H}_{1 \mathrm{~b}}$ & $\mathrm{H}_{2}$ & $\mathrm{H}_{\mathrm{NMel}}$ & $\mathrm{H}_{\mathrm{NMe} 2}$ & $\mathrm{C}_{1}$ & $\mathrm{C}_{2}$ & $\mathrm{C}_{\mathrm{NMe1}}$ & $\mathrm{C}_{\mathrm{NMe} 2}$ & \\
\hline$\left(\mathrm{P}^{\wedge} \mathrm{N}\right) \mathrm{Au}-\mathrm{Cl}$ & \multicolumn{3}{|c|}{-} & \multicolumn{2}{|c|}{2.57} & \multicolumn{2}{|c|}{-} & \multicolumn{2}{|c|}{47.0} & 53.6 \\
\hline$\left(P^{\wedge} N\right)$ & \multicolumn{2}{|c|}{$\begin{array}{c}7.76 \\
(6.34)\end{array}$} & $\begin{array}{c}4.78 \\
(4.64)\end{array}$ & 2.74 & 2.71 & $\begin{array}{l}144.1 \\
(144.3)\end{array}$ & $\begin{array}{c}76.7 \\
(100.7)\end{array}$ & 49.5 & 49.3 & 56.5 \\
\hline$\left(\mathrm{P}^{\wedge} \mathrm{N}\right) \stackrel{\oplus \mathrm{Au}}{\stackrel{\mathrm{I}}{\mathrm{L}}}$ & $\begin{array}{c}4.33 \\
(5.74)\end{array}$ & $\begin{array}{c}4.17 \\
(5.24)\end{array}$ & $\begin{array}{c}6.03 \\
(6.72)\end{array}$ & 3.09 & 2.82 & $\begin{array}{c}66.4 \\
(113.7)\end{array}$ & $\begin{array}{c}99.9 \\
(136.9)\end{array}$ & 53.0 & 52.8 & 57.3 \\
\hline 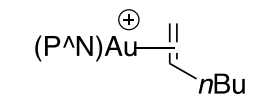 & $\begin{array}{c}3.94 \\
(4.95)\end{array}$ & $\begin{array}{c}3.76 \\
(4.87)\end{array}$ & $\begin{array}{c}5.66 \\
(5.78)\end{array}$ & 3.01 & 2.98 & $\begin{array}{c}75.2 \\
(116.0)\end{array}$ & $\begin{array}{c}111.1 \\
(139.0)\end{array}$ & 52.5 & 52.5 & 58.1 \\
\hline$\left(\mathrm{P}^{\wedge N}\right) \stackrel{\oplus}{\stackrel{\oplus}{u}} \|$ & & $\begin{array}{c}4.10 \\
(5.43)\end{array}$ & & & & $\begin{array}{r}75 \\
(11\end{array}$ & & & .9 & 58.8 \\
\hline$\left(\mathrm{P} \wedge^{\wedge}\right) \stackrel{\oplus}{\stackrel{\oplus}{A}}$ & & - & & & & $\begin{array}{r}97 \\
(80\end{array}$ & & & .9 & 59.4 \\
\hline 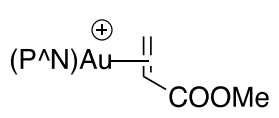 & $\begin{array}{c}4.35 \\
(6.40)\end{array}$ & $\begin{array}{c}4.61 \\
(5.82)\end{array}$ & $\begin{array}{l}4.23 \\
(6.13)\end{array}$ & 3.25 & 3.07 & $\begin{array}{c}68.4 \\
(130.6)\end{array}$ & $\begin{array}{c}72.5 \\
(128.5)\end{array}$ & 54.9 & 53.8 & 63.2 \\
\hline$\left(\mathrm{P}^{\wedge} \mathrm{N}\right) \mathrm{Au}^{\oplus}$ & & $\begin{array}{l}68 \\
81)\end{array}$ & $\begin{array}{c}5.67 \\
(6.81)\end{array}$ & 3.44 & 3.33 & $\begin{array}{c}68.8 \\
(134.1)\end{array}$ & $\begin{array}{c}72.4 \\
(134.1)\end{array}$ & 55.4 & 55.2 & 65.3 \\
\hline
\end{tabular}

All data recorded in $\mathrm{CD}_{2} \mathrm{Cl}_{2}$. ${ }^{1} \mathrm{H}$ and ${ }^{13} \mathrm{C}$ NMR data from the free alkenes or alkyne are indicated in brackets.

Similarly to the styrene and ethylene complexes, the DHP, MA and NPM $\pi$-complexes present structures in the solid state with the $\mathrm{P}^{\wedge} \mathrm{N}$ ligand chelating gold and a trigonal planar environment around the gold center (Figure 7). In all cases, the alkene is $\eta^{2}$-coordinated and sits in the $\left[\left(\mathrm{P}^{\wedge} \mathrm{N}\right) \mathrm{Au}\right]^{+}$coordination plane despite the ensuing steric shielding. Of note, $\eta^{2}$-coordination for a complex with an electron-rich DHP was unprecedented (terminal $\sigma$-coordination rather than side-on $\pi$-coordination was found in dicoordinate gold(I) $\pi$-complexes with electron-rich alkenes). ${ }^{36,99,100,101,102,103}$ The three complexes showed an elongation of the $\mathrm{C}=\mathrm{C}$ bond upon coordination, indicating significant gold $\rightarrow$ alkene backdonation. The $\mathrm{Au}-\mathrm{C}$ and $\mathrm{Au}-\mathrm{P}$ bond lengths show little changes along the series, whereas the $\mathrm{Au}-\mathrm{N}$ bond length varies from 2.234(6) $\AA$ in the NPM complex (the most electron-poor alkene) to 2.505(2) $\AA$ in the DHP complex (the most electron-rich alkene) (Table 2). This variation, together with the NMR spectroscopic data 
of the $\mathrm{N}\left(\mathrm{CH}_{3}\right)_{2}$ group, attested the versatility and adaptive behavior of the $\mathrm{P}^{\wedge} \mathrm{N}$ ligand to strengthen/weaken the $\mathrm{N}-\mathrm{Au}$ interaction to accommodate the electronic demand at gold depending on the alkene. Theoretical calculations further supported both the strong $\mathrm{d}(\mathrm{Au}) \rightarrow \pi^{*}(\mathrm{C}=\mathrm{C})$ backdonation, and the ability of the $\mathrm{P}^{\wedge} \mathrm{N}$ ligand to accommodate the $\pi$ coordination of a wide range of alkenes at gold. In addition, a detailed examination of the structural, electronic and spectroscopic data collected experimentally and computationally revealed a direct and linear response of the $\mathrm{P}^{\wedge} \mathrm{N}$ MeDalphos ligand to the $\mathrm{Au} /$ alkene coordination along the series of gold(I) $\pi$-complexes (Figure 8).

Table 2. Selected bond lengths $(\AA)$ for the $\pi$-alkene gold(I) complexes 19, 20, 23-25.

\begin{tabular}{|c|c|c|c|c|c|}
\hline$\stackrel{\text { Aut }}{ }$ & & $\|_{P h}$ & $\|$ & coome & \\
\hline $\mathrm{Au}-\mathrm{P}$ & $2.3032(6)$ & $2.337(1)$ & $2.3393(5)$ & $2.326(1)$ & $2.334(2)$ \\
\hline $\mathrm{Au}-\mathrm{N}$ & $2.505(2)$ & $2.381(4)$ & $2.306(2)$ & $2.275(5)$ & $2.234(6)$ \\
\hline $\mathrm{Au}-\mathrm{C}$ & $\begin{array}{l}2.276(3) \\
2.193(3)\end{array}$ & $\begin{array}{l}2.208(5) \\
2.143(5)\end{array}$ & $\begin{array}{l}2.141(3) \\
2.149(3)\end{array}$ & $\begin{array}{l}2.114(6) \\
2.155(6)\end{array}$ & $\begin{array}{l}2.133(8) \\
2.136(7)\end{array}$ \\
\hline $\mathrm{C}=\mathrm{C}$ & $1.385(5)$ & $1.387(8)$ & $1.387(5)$ & $1.406(10)$ & $1.394(12)$ \\
\hline
\end{tabular}
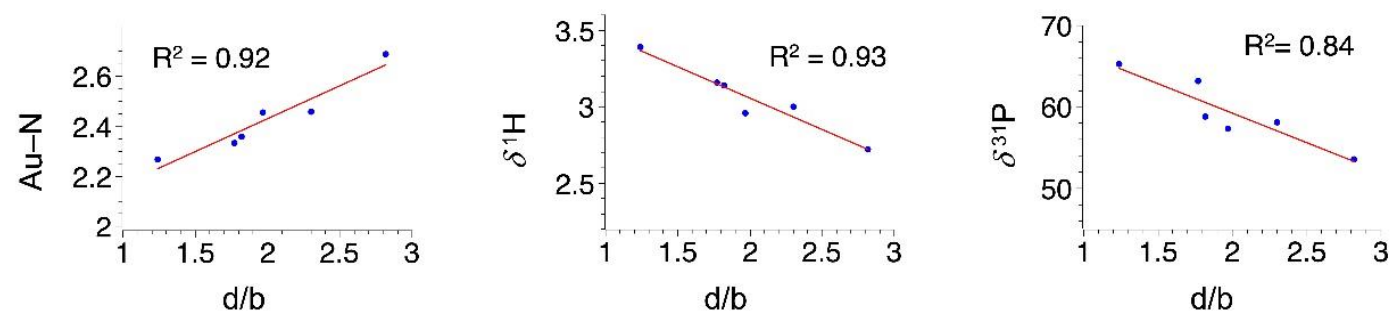

Figure 8. Correlation graphs for the response of the $\mathrm{P}^{\wedge} \mathrm{N}$ ligand ( $\mathrm{Au}-\mathrm{N}$ distance in $\AA$, ${ }^{1} \mathrm{H}$ NMR chemical shift of the $\mathrm{NMe}_{2}$ group and ${ }^{31} \mathrm{P}$ NMR chemical shift in $\mathrm{ppm}$ ) to the alkene coordination to gold characterized by the donation/backdonation ratio $\mathrm{d} / \mathrm{b}$, as determined by Charge Decomposition Analyses.

\subsection{Comparison of Gold(I) ethylene complexes with chelating and hemilabile ligands}

No gold(I) ethylene complex has been reported with monodentate ancillary ligands, but as aforementioned, chelating ligands have proved powerful to stabilize such complexes. Hereafter are gathered all the known tricoordinate gold(I) ethylene complexes, showing the variety of $\mathrm{N}$ 
and P-based chelating/hemilabile ligands used so far. The ${ }^{1} \mathrm{H}$ and ${ }^{13} \mathrm{C}$ NMR chemical shifts, and the $\mathrm{C}=\mathrm{C}$ bond distances of the coordinated ethylene are listed in Table 3.

Table 3. Comparison between reported $\mathrm{Au}(\mathrm{I})$ ethylene complexes and free ethylene.

\begin{tabular}{|c|c|c|c|c|c|}
\hline Compound & $\begin{array}{l}\text { Ligand } \\
\text { type }\end{array}$ & $\delta{ }^{1} \mathrm{H}(\mathrm{ppm})$ & $\delta^{13} \mathrm{C}(\mathrm{ppm})$ & $\mathrm{C}=\mathrm{C}(\AA)$ & Ref \\
\hline & - & 5.43 & 116.8 & 1.313 & 72 \\
\hline & - & 4.94 & 92.7 & $\begin{array}{l}1.371(7) \\
1.351(7) \\
1.369(7)\end{array}$ & 83 \\
\hline & $\begin{array}{c}\text { Neutral } \\
\mathrm{N}^{\wedge} \mathrm{N}\end{array}$ & 3.09 & 61.6 & - & 66 \\
\hline & $\begin{array}{c}\text { Anionic } \\
\mathrm{N}^{\wedge} \mathrm{N}\end{array}$ & $\begin{array}{l}3.81(\mathbf{6 a}) \\
3.69(\mathbf{6 b}) \\
2.61(\mathbf{7 a}) \\
3.00(\mathbf{7 b})\end{array}$ & $\begin{array}{l}63.7(\mathbf{6 a}) \\
59.3(\mathbf{6 b}) \\
55.3(\mathbf{7 a}) \\
56.9(7 \mathbf{b})\end{array}$ & $\begin{array}{c}1.380(10)(6 \mathbf{6}) \\
1.387(9)(\mathbf{6 b}) \\
1.413(7)(7 \mathbf{a}) \\
1.410(5)(7 \mathbf{b})\end{array}$ & 69,75 \\
\hline & $\begin{array}{c}\text { Anionic } \\
\mathrm{N}^{\wedge} \mathrm{N}\end{array}$ & 2.71 & 59.1 & $1.405(4)$ & 77 \\
\hline & $\begin{array}{c}\text { Neutral } \\
\mathrm{N}^{\wedge} \mathrm{N}\end{array}$ & $\begin{array}{l}3.31 \\
3.28\end{array}$ & 65.4 & $1.455(13)$ & 82 \\
\hline & $\begin{array}{c}\text { Neutral } \\
\mathrm{N}^{\wedge} \mathrm{N}\end{array}$ & 3.90 & 63.8 & $1.399(5)$ & 84 \\
\hline & $\begin{array}{c}\text { Neutral } \\
\mathrm{N}^{\wedge} \mathrm{N}\end{array}$ & 3.88 & 60.6 & $\begin{array}{c}1.411(10) \\
1.383(8)\end{array}$ & 92 \\
\hline & $\begin{array}{c}\text { Neutral } \\
P^{\wedge} \mathrm{P}\end{array}$ & 4.47 & 74.0 & $1.387(5)$ & 96 \\
\hline & $\begin{array}{c}\text { Neutral } \\
\mathrm{P}^{\wedge} \mathrm{N}\end{array}$ & 4.10 & 75.0 & $1.365(15)$ & 96 \\
\hline
\end{tabular}




\section{Gold(I) carbene complexes}

Gold(I) carbene complexes have been known for several decades. The first Fischer-type gold(I) carbene complexes $\mathrm{Cl}-\mathrm{Au}=\mathrm{C}(\mathrm{X}) \mathrm{Ph}\left(\mathrm{X}=\mathrm{OMe}, \mathrm{NH}_{2}, \mathrm{NHMe}, \mathrm{NMe}_{2}\right)$ were reported by Fischer himself as early as in 1981. ${ }^{104,105}$ About 20 years later, a series of cationic Fischer-type gold(I) carbene complexes featuring an NHC or a phosphine as ancillary ligand were structurally characterized (Figure 9). ${ }^{106,107,108}$ The presence of a $\pi$-donating OMe group at the carbene center reduces the reactivity. These complexes feature little ordinary carbene character and are best described by their carbocationic form. The $\mathrm{Au}-\mathrm{C}$ bond order is very close to one and the $\mathrm{C}-\mathrm{O}$ distance is significantly contracted.<smiles>[X]C([R])=[Al]CC</smiles>

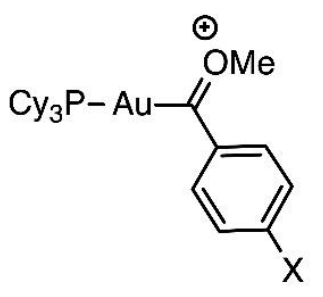

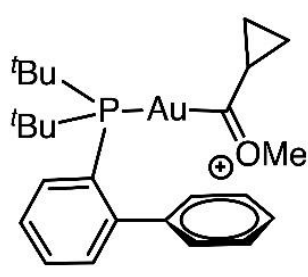

$\mathrm{X}=\mathrm{H}$ or $\mathrm{OMe}$

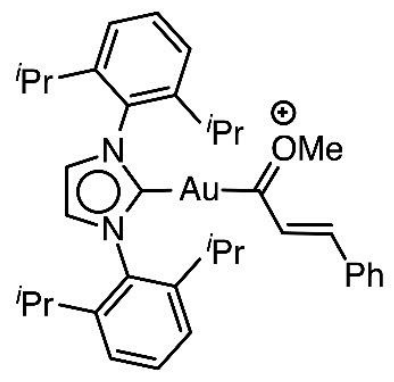

Figure 9. Carbene and carbocationic forms of gold(I) carbenes; some structurally characterized Fischer-type gold(I) carbene complexes.

Since the first isolation of a $N$-heterocyclic carbene gold(I) complexes in $1973,{ }^{109}$ a number of NHC gold(I) complexes [(NHC)AuCl] have been prepared taking advantage of the many straightforward synthetic routes. ${ }^{110}$ Notably, NHC-gold complexes have shown great potential in biological applications, ${ }^{111}$ luminescent devices ${ }^{112}$ and as catalysts in many organic transformations. ${ }^{113}$ Besides the use of carbenes as ancillary ligands, gold(I) carbenoid species have been postulated as intermediate species in many transformations induced by gold catalysts. Therefore, the preparation and characterization of gold(I) carbene complexes has captured growing interest in the last years despite the difficulties of stabilizing such reactive species and gathering useful structural information. For instance, in 2013 Widenhoefer et al managed to observe spectroscopically at low temperature a gold carbenoid intermediate formed by a prototype 
enyne rearrangement for the first time. ${ }^{114}$ Most of the gold(I) carbene complexes reported to date are stabilized by $\pi$ conjugation of the electro-deficient carbenoid center with heteroatoms. ${ }^{106,107,108}$ In 2014, Fürstner et al described the first stable gold(I) carbene 26 without heteroatomic substituent (Figure 10). ${ }^{106}$ According to $\mathrm{X}$-ray diffraction analysis, there is little $\mathrm{Au} \rightarrow \mathrm{C}_{\text {carbene }}$ back donation and hence very modest $\mathrm{Au}-\mathrm{C}$ double-bond character. The electron deficiency of the carbene center is tempered by $\pi$-delocalization of the electron-rich aryl substituents. In the same year, Widenhoefer et al reported a gold(I) cycloheptatrienylidene complex 27. Here, the carbene moiety is integrated into a $6 \pi$-electron aromatic ring (Figure 10). ${ }^{115}$ In a parallel study, Straub et al prepared and fully characterized a stable diaryl gold(I)-carbene complex $\mathbf{2 8}$. The carbene center is substituted by two Mes groups and a very bulky NHC is used as ancillary ligand, resulting in very strong steric shielding of the carbenoid moiety (Figure 10). ${ }^{116}$

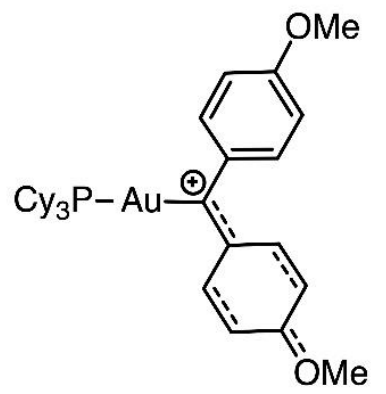

26

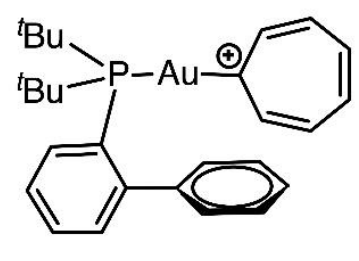

27

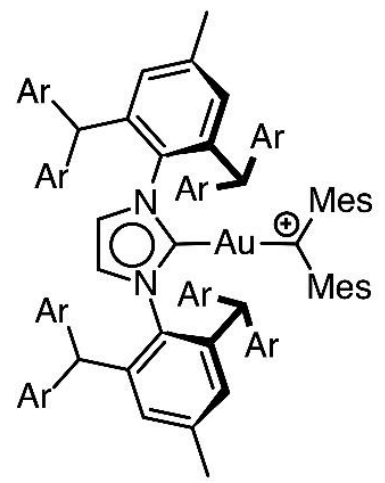

28

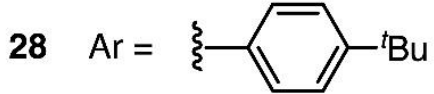

Figure 10. Non-heteroatom substituted gold(I) carbene complexes featuring phosphine / NHC ancillary ligands.

In 2014, our group took advantage of the chelating properties of the $o$-carboranyl diphosphine ligand to synthetize and fully characterize the first classical carbonyl complex of gold. ${ }^{97}$ The bent $\mathrm{PAuP}^{+}$fragment is crucial to raise the energetic level of the occupied $\mathrm{d}_{x z}(\mathrm{Au})$ orbital and enhance $\pi$-backdonation. Inspired by the unusual electronic structure of the gold carbonyl complex, we targeted the first carbene complex stabilized by the gold fragment rather than the carbene substituents. Reaction of $\left[\left(\mathrm{P}^{\wedge} \mathrm{P}\right) \mathrm{AuNTf}_{2}\right]$ with diphenyldiazomethane at low temperature $\left(-40^{\circ} \mathrm{C}\right)$ afforded the gold(I) carbene complex $\left[\left(\mathrm{P}^{\wedge} \mathrm{P}\right) \mathrm{Au}\left(\mathrm{CPh}_{2}\right)\right]^{+} \mathbf{2 9}$ in excellent yield as a highly thermally stable solid (Scheme 10). ${ }^{97}$ The gold center is arranged in a trigonal-planar environment, in which the DPCb ligand chelates the gold center with a bite angle of $90.26(4)^{\circ}$, similar to those observed in the $\pi$-complexes $\mathbf{1 7}$ and $\mathbf{1 8}\left(89.12(2)^{\circ}\right.$ and $\left.91.32(7)^{\circ}\right)$. The carbene center is perfectly planar and almost perpendicular to the $\left[\left(\mathrm{P}^{\wedge} \mathrm{P}\right) \mathrm{Au}\right]^{+}$coordination plane (with a twist angle of $\left.85.2^{\circ}\right)$. This 
orientation minimizes steric repulsion and enables optimal interaction between the high-energy occupied $d_{x z}(\mathrm{Au})$ orbital in the plane of the $\left[\left(\mathrm{P}^{\wedge} \mathrm{P}\right) \mathrm{Au}\right]^{+}$fragment and the vacant $2 \mathrm{p}$ orbital at the carbene center. The $\mathrm{Au}-\mathrm{C}_{\text {carbene }}$ bond is slightly shorter (1.984 $\AA$ ) to those of complexes $\mathbf{2 6}-\mathbf{2 8}$. Optimization of the geometry by DFT calculations and NBO analysis corroborated the bonding interaction between the $\mathrm{d}_{x z}(\mathrm{Au})$ and $2 \mathrm{p}^{\pi}(\mathrm{C})$ orbitals in the coordination plane of gold, indicating significant carbene $\pi$-backdonation and some degree of $\mathrm{Au}-\mathrm{C} \pi$ bonding.
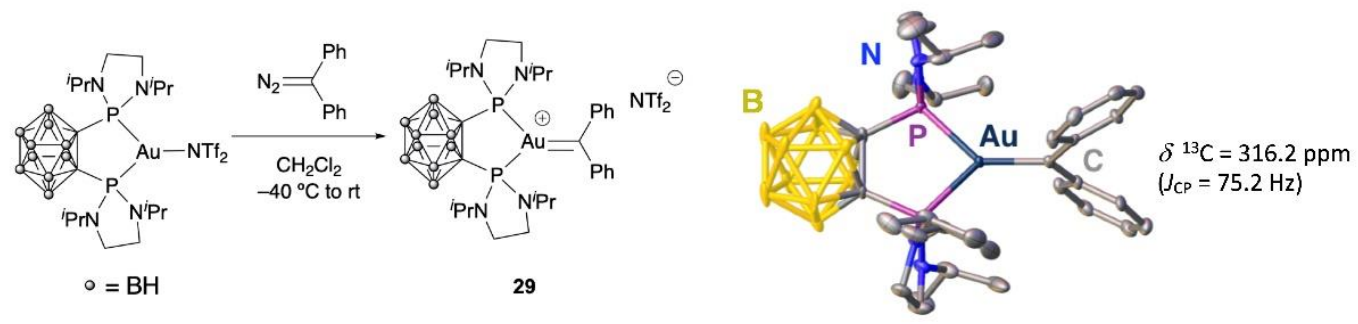

Scheme 10. Synthesis and structure of the $\mathrm{P}^{\wedge} \mathrm{P}$ gold carbene complex.

The easy generation and versatile reactivity of $\alpha$-oxo gold carbene complexes was recognized in the early 2000s, giving rise to numerous applications in gold catalysis. ${ }^{117,118,119}$ In a pioneering work of Pérez and Nolan, the reaction of $\alpha$-diazo carbonyl compounds with phosphine and NHC gold(I) precursors proved to be a very efficient and general route to generate highly electrophilic $\alpha$-oxo carbene intermediates ${ }^{120,121}$ of many carbene transfer ${ }^{122,123,124,125,126}$ and coupling ${ }^{127,128}$ catalytic reactions. Despite their role as key intermediates, gold(I) $\alpha$-oxo carbene complexes have remained elusive for many years. ${ }^{129,130,131}$ Remarkably, the group of Zhang developed a $\mathrm{Au}(\mathrm{I})$ catalyzed modular synthesis of 2,4-disubstituted oxazoles via [3+2] annulations between alkynes and aromatic/alkenic carboxamides under mild conditions. ${ }^{132,133,134,135} \mathrm{~A}$ highly electrophilic $\alpha$ oxo gold(I) carbene generated via gold-promoted oxidation of a terminal alkyne was postulated as the key reaction intermediate (Scheme 11). However, the use of $\mathrm{P}^{\wedge} \mathrm{N}$ or $\mathrm{P}^{\wedge} \mathrm{S}$ bidentate ligands, especially MorDalphos-type ligands, ${ }^{136}$ significantly tempered its reactivity, permitting its efficient trapping by a carboxamide en route to the formation of the oxazole ring. The formation of a tricoordinate gold(I) carbene species 30 by coordination of the $\mathrm{N}$ or $\mathrm{S}$ atom was proposed to reduce the electrophilicity of the carbene center. ${ }^{137,138,139}$ 


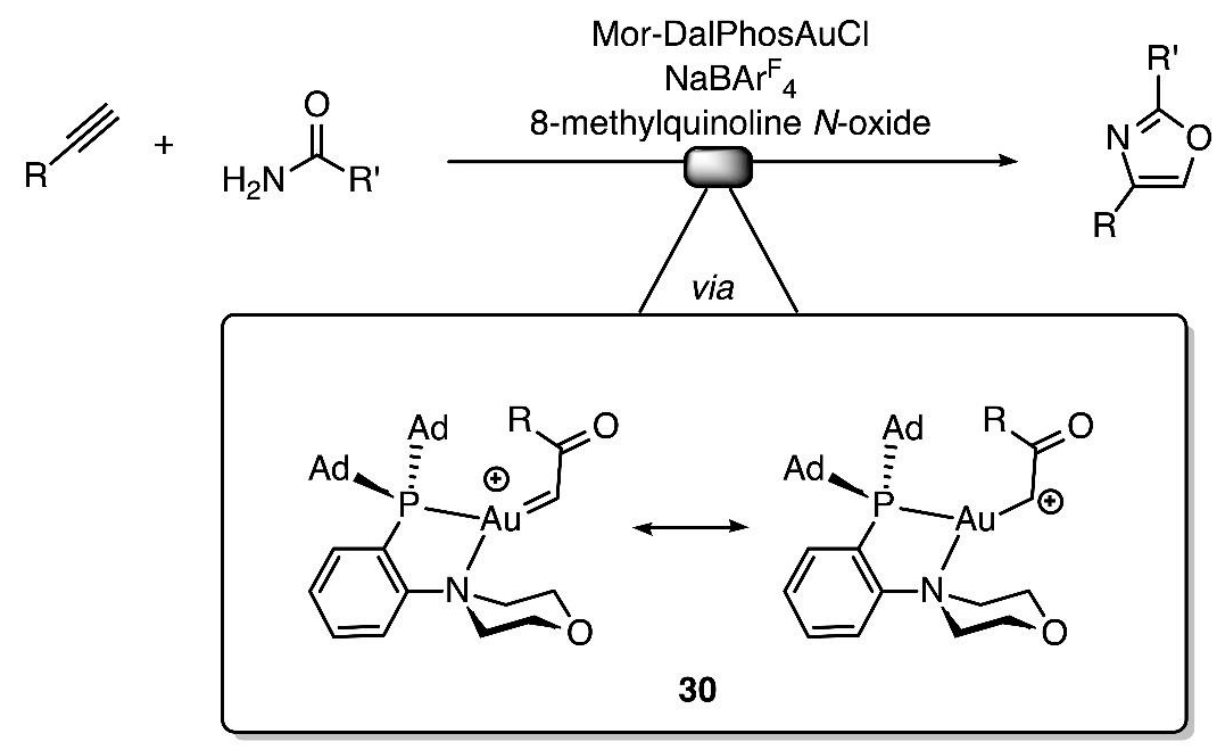

Scheme 11. Gold(I)-catalyzed synthesis of 2,4-disubstituted oxazoles through the generation of a $\left(\mathrm{P}^{\wedge} \mathrm{N}\right)$-chelated $\alpha$-oxo gold carbene $\mathbf{3 0}$.

In view of the studies on gold(I) $\alpha$-oxo carbene complexes stabilized by $\mathrm{P}^{\wedge} \mathrm{N}$ and $\mathrm{P}^{\wedge} \mathrm{S}$ chelating ligands, together with the unprecedented reactivity and bonding situation induced by the $\mathrm{P}^{\wedge} \mathrm{N}$ bidentate ligand MeDalphos, ${ }^{15,16,17}$ our group envisioned that a tricoordinate $\alpha$-oxo carbene gold(I) complex could be generated by reacting the $\alpha$-diazo ester $\mathrm{PhC}\left(=\mathrm{N}_{2}\right) \mathrm{CO}_{2}$ Et with the $[(\mathrm{MeDalphos}) \mathrm{AuCl}]$ precursor in the presence of $\mathrm{AgSbF}_{6}$ (Scheme 12). ${ }^{140}$ However, despite in situ and low-temperature NMR monitoring, the proposed $\left[\left(\mathrm{P}^{\wedge} \mathrm{N}\right) \mathrm{Au}=\mathrm{C}(\mathrm{Ph}) \mathrm{CO}_{2} \mathrm{Et}\right]^{+} \mathbf{3 1}$ was not detected. Its geometry was optimized by DFT (Scheme 12) and an NBO analysis was carried out. This revealed a $\mathrm{Au} \cdots \mathrm{N}$ distance of $2.53 \AA$, which is relatively long [ $46 \%$ shorter than the $\Sigma r_{\mathrm{VdW}}$ $(3.07 \AA)^{74}$ but $22 \%$ longer than the $\left.\Sigma r_{\text {cov }}(2.07 \AA)\right] .{ }^{141}$ In addition, the $\mathrm{P}-\mathrm{Au}-\mathrm{C}_{\text {carbene }}$ arrangement is almost linear $\left(163.3^{\circ}\right)$, and thus with the absence of a significant $\mathrm{N}$ to Au coordination the gold center becomes electron-deficient with a significant transfer of electron density from the carbene to the metal $($ Charge Transfer $=0.8 \mathrm{e}$ ). This bonding situation explains the high electrophilicity and instability of the proposed carbene complex. 


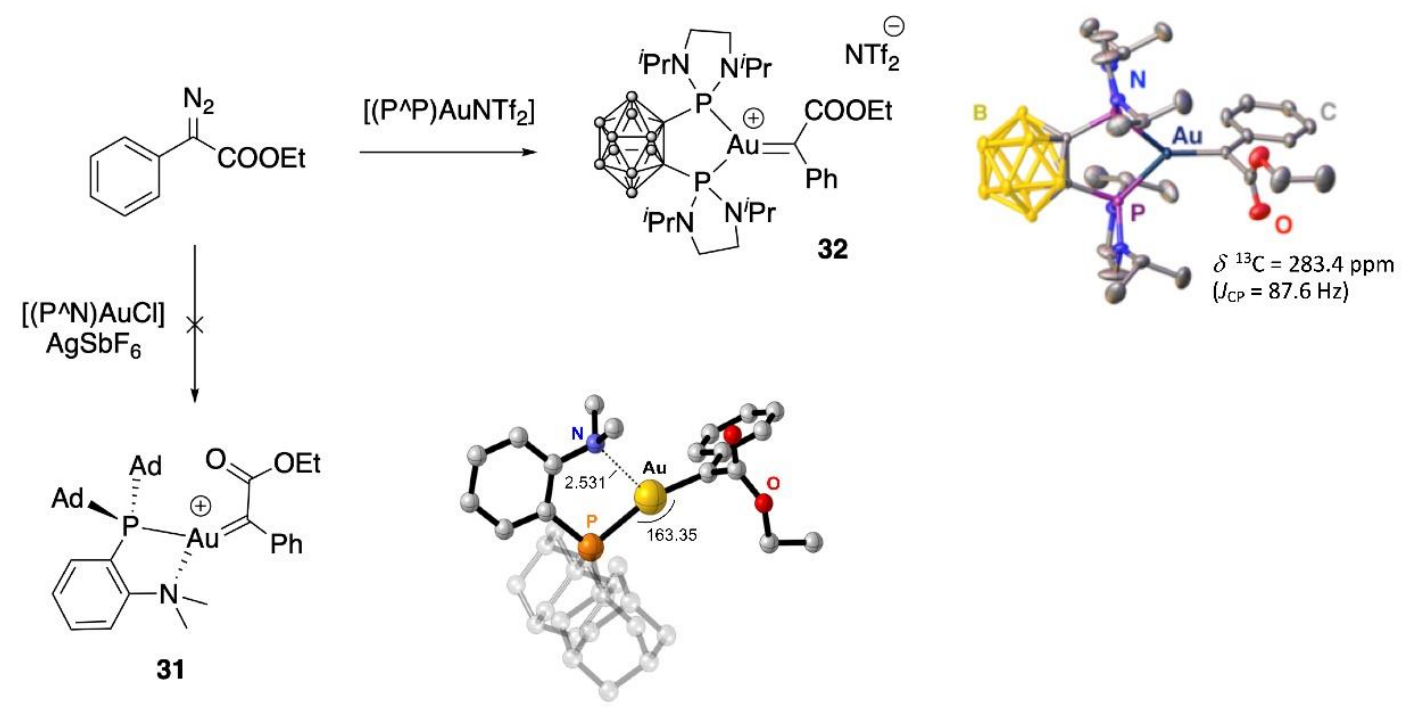

Scheme 12. $\alpha$-Oxo gold(I) carbene complexes with chelating $\mathrm{P}^{\wedge} \mathrm{P}$ and $\mathrm{P}^{\wedge} \mathrm{N}$ ligands: (attempted) synthesis, DFT-optimized and cristallographically-determined structures.

On the other hand, reaction of the $o$-carboranyl diphosphine gold(I) precursor with $\mathrm{PhC}\left(=\mathrm{N}_{2}\right) \mathrm{CO}_{2} \mathrm{Et}$ at $-40{ }^{\circ} \mathrm{C}$ was accompanied by immediate dinitrogen evolution, and generated the $\alpha$-oxo carbene gold(I) complex 32 (Scheme 12). The $\left[\left(\mathrm{P}^{\wedge} \mathrm{P}\right) \mathrm{Au}=\mathrm{C}(\mathrm{Ph}) \mathrm{CO}_{2} \mathrm{Et}\right]^{+}$complex was found to be thermally unstable (decomposition is quite fast above $0{ }^{\circ} \mathrm{C}$ ). It was characterized spectroscopically at low temperature and crystals suitable for X-ray diffraction analysis could be obtained. ${ }^{31} \mathrm{P}$ NMR spectroscopy showed a single resonance signal at $\delta=138.9 \mathrm{ppm}$, indicative of symmetric coordination of the phosphorus atoms to gold. In addition, ${ }^{13} \mathrm{C}$ NMR spectroscopy showed a characteristic carbene resonance signal appearing as a triplet $\left(J_{\mathrm{CP}}=87.6 \mathrm{~Hz}\right)$ at 283.4 $\mathrm{ppm}$, which is in the range of previously characterized gold(I) carbenoid complexes. As apparent from the solid-state structure, the gold center is arranged in a trigonal-planar environment with the DPCb ligand coordinated in a $\kappa^{2}$-coordination fashion. The $\mathrm{P}-\mathrm{Au}-\mathrm{P}$ bite angle of $90.26(4)^{\circ}$ is similar to those observed in related $\left[\left(\mathrm{P}^{\wedge} \mathrm{P}\right) \mathrm{Au}-\mathrm{L}\right]^{+}$complexes $\left(\mathrm{L}=\right.$ styrene, ethylene, $\mathrm{CO}$ or $\left.\mathrm{CPh}_{2}\right)$. The Au-C bond distance (1.961(2) $\AA$ ) is in the shortest range of those reported for gold carbene complexes. Of note, the phenyl ring is nearly co-planar with the carbene center and the $\mathrm{C}_{\text {carbene- }}{ }^{-}$ $\mathrm{C}_{\mathrm{ipso}}$ bond is slightly contracted (1.448(4) $\AA$ ) indicating a certain degree of $\pi$-delocalization between the phenyl ring and the carbene center, thus stabilizing the carbene species. NBO analysis revealed $\pi_{\mathrm{C}=\mathrm{C}}(\mathrm{Ph}) \rightarrow 2 \mathrm{p}^{\pi}(\mathrm{C})$ and $\mathrm{n}_{\mathrm{C}}{ }^{\sigma} \rightarrow \pi^{*} \mathrm{C}=\mathrm{O}$ donor-acceptor interactions indicating push-pull stabilization of the $\alpha$-oxo carbene. In addition, a significant $d_{x z}(A u) \rightarrow 2 p^{\pi}(C)$ backdonation was also apparent. Charge transfer (CT) and charge-decomposition analysis (CDA) indicated the relative contributions of $\mathrm{C}_{\text {carbene }} \rightarrow \mathrm{Au}$ donation and $\mathrm{Au} \rightarrow \mathrm{C}_{\text {carbene }}$ backdonation with a d/b ration of 1.76, which is significantly smaller than that computed for the $\left[\left(\mathrm{P}^{\wedge} \mathrm{N}\right) \mathrm{Au}=\mathrm{C}(\mathrm{Ph}) \mathrm{CO}_{2} \mathrm{Et}\right]^{+}$analogue $(\mathrm{d} / \mathrm{b}=2.16)$, supporting a lower electrophilicity and higher stability of the $\mathrm{P}^{\wedge} \mathrm{P}$-chelated complex (Figure 11). 

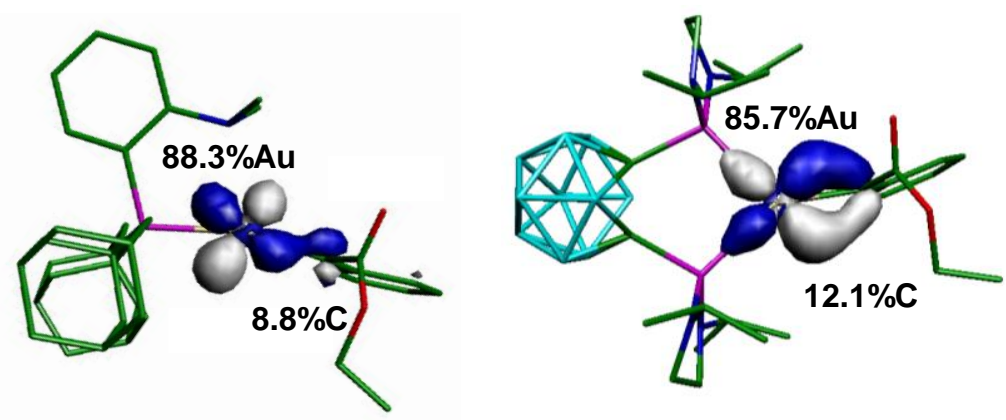

Figure 11. Plots of the NLMO associated with the $d_{x z}(A u) \rightarrow 2 p^{\pi}(C)$ backdonation in the $\alpha$-oxo carbene gold(I) complexes featuring either $\mathrm{P}^{\wedge} \mathrm{N}$ or $\mathrm{P}^{\wedge} \mathrm{P}$ chelating ligand (with the contributions of the gold and $\mathrm{C}_{\text {carbene }}$ atoms in percent).

In 2009, Toste et al reported a detailed investigation of the bonding situation in gold(I) carbenoid complexes. The influence of the carbene substituents and ancillary ligand at gold on the structure (carbene versus carbocationic form) and reactivity was analyzed. ${ }^{142} \mathrm{~A}$ few years later, Kästner, Hashmi et al also studied stabilizing effects in gold(I) carbene complexes by Intrinsic Bond Orbital (IBO) calculations. ${ }^{143}$ Again, $\pi$-stabilization through delocalization or by the presence of heteroatoms in $\alpha$ position of the carbene center appeared crucial for the stabilization of gold(I) carbene complexes. In addition, $\mathrm{C}_{\text {carbene }}$ to gold $\sigma$-donation was found to prevail in the $\mathrm{Au}-\mathrm{C}$ bonding. It is similar for di and tricoordinate gold(I) carbene complexes, however $\pi$-backdonation is significantly higher in tricoordinate complexes ( 0.175 versus 0.074$)$, in line with the electronic properties of the bent $\mathrm{P}-\mathrm{Au}-\mathrm{P}^{+}$fragment.

To demonstrate that the $\mathrm{P}^{\wedge} \mathrm{P}-\mathrm{Au} \alpha$-oxo carbene 32 complex can be indeed considered as a mimic of transient species, different representative transformations were tested, first in stoichiometric and then in catalytic conditions. Reaction of styrene with the $\alpha$-diazo ester in the presence of 5 mol\% of $\left[\left(\mathrm{P}^{\wedge} \mathrm{P}\right) \mathrm{AuNTf}_{2}\right]$ afforded the cyclopropane derivative 33 in $58 \%$ yield after $64 \mathrm{~h}$ at room temperature (Scheme 13). The $\mathrm{Au}(\mathrm{I})$ carbene complex also reacted with $\mathrm{Ph}_{3} \mathrm{P} \rightarrow \mathrm{BH}_{3}$ to give the $\mathrm{B}-\mathrm{H}$ insertion product 34 in $60 \%$ yield after $30 \mathrm{~min}$. In addition, the $\mathrm{Au}(\mathrm{I})$ carbene complexes reacted with phenol ( $60 \%$ yield after $2 \mathrm{~h}$ ) to give the $\mathrm{O}-\mathrm{H}$ insertion aryl ether product $\mathbf{3 5}$ (Scheme 13). This $\mathrm{O}-\mathrm{H}$ insertion differs from the reported monoligated phosphine gold(I) complexes. ${ }^{125,144}$ Gold carbene complexes possess unique propensity to insert into the para $\mathrm{C}-\mathrm{H}$ bond, enabling the direct and selective functionalization of unprotected phenols. Chemoselectivity for $\mathrm{C}-\mathrm{H}$ versus $\mathrm{O}-\mathrm{H}$ insertion is favored with electron-deprived phosphine ligands, which increase the electrophilicity of the $\alpha$-oxo carbene intermediate. However, the $\mathrm{P}^{\wedge} \mathrm{P}$ ligand strengthens the $\mathrm{Au} \rightarrow \mathrm{C}_{\text {carbene }}$ backdonation and decreases the electrophilicity of the carbene switching the chemoselectivity towards $\mathrm{O}-\mathrm{H}$ insertion leading to the formation of the aryl ether. ${ }^{145}$ 

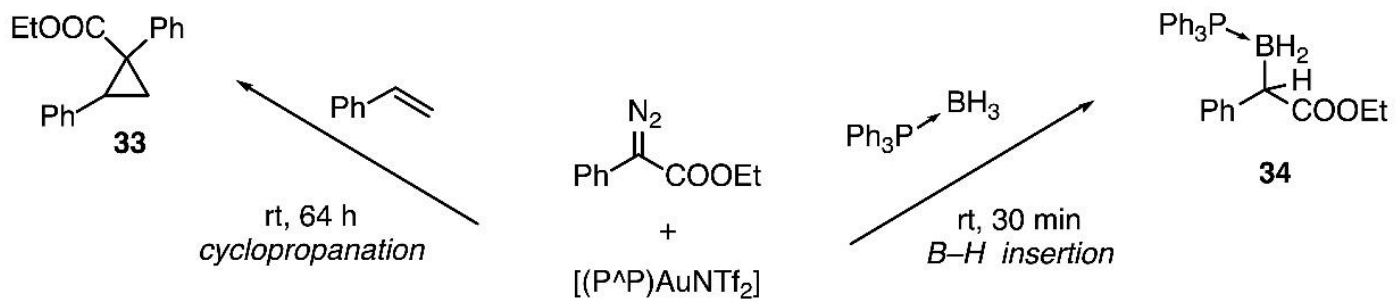

34

(5 mol\%)
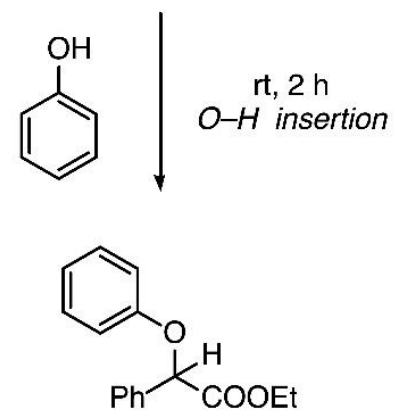

35

Scheme 13. Gold carbene reactivity upon reaction of a-diazo ester with styrene, triphenylphosphine-borane, and phenol catalyzed by the $\left[\left(\mathrm{P}^{\wedge} \mathrm{P}\right) \mathrm{AuNTf}_{2}\right]$ complex.

The use of an $\alpha$-diazo ester with electron-withdrawing groups $\left(\mathrm{CF}_{3}\right.$ groups) in remote positions was evaluated to confirm the critical role of the gold carbene electrophilicity. In this case, the functionalized phenol $\mathbf{3 6}$ derived from $\mathrm{C}-\mathrm{H}$ insertion was obtained as major product along with some aryl ether 37 (Scheme 14). According to DFT calculations, the frontier orbitals of the $\left(\mathrm{F}_{3} \mathrm{C}\right)_{2} \mathrm{Ph}$-substituted gold carbene are noticeably lower in energy than those of the corresponding $\mathrm{Ph}$-substituted gold carbene. The resulting $\mathrm{P}^{\wedge} \mathrm{P}$-chelated gold carbene actually resembles the $\left[\left(\mathrm{P}^{\wedge} \mathrm{N}\right) \mathrm{AuC}(\mathrm{Ph}) \mathrm{CO}_{2} \mathrm{Et}\right]^{+}$complex in carbene electrophilicity, which explains why $\mathrm{C}-\mathrm{H}$ insertion prevails in this case.<smiles>CCOC(=N)c1cc(C(F)(F)F)cc(C(F)(F)F)c1</smiles>

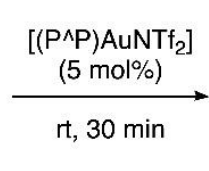<smiles>CCOC(OCC)(c1ccc(O)cc1)c1cc(C(F)(F)F)cc(C(F)(F)F)c1</smiles>

$36(68 \%)$<smiles>CCOC(Oc1ccccc1)(Oc1cc(C(F)(F)F)cc(C(F)(F)F)c1)c1ccccc1</smiles>

$37(32 \%)$

Scheme 14. C-H versus $\mathrm{O}-\mathrm{H}$ functionalization of phenol with the $\alpha$-diazo ester catalyzed by the $\left[\left(\mathrm{P}^{\wedge} \mathrm{P}\right) \mathrm{AuNTf}_{2}\right]$ complex. 
Extending the variety of stable reactive gold(I) carbene complexes is an obvious outlook of the recent advances, in particular with respect to the substitution pattern at the carbene. In a recent study, Echavarren et al generated and spectroscopically characterized for the first time a monosubstituted gold(I) carbene in solution. ${ }^{146}$ The reaction of the gold(I) complexes bearing JohnPhos-type ligands $\mathbf{3 8}$ with mesityl diazomethane first afforded the corresponding gold(I) carbenoids 39 (Scheme 15). Subsequently, addition of $\mathrm{GaCl}_{3}$ at $-90{ }^{\circ} \mathrm{C}$ generated the gold(I) carbenes 40, which are stable only below $-70{ }^{\circ} \mathrm{C}$. The monosubstituted gold(I) carbene complexes were characterized spectroscopically at low temperature, presenting a characteristic signal in ${ }^{1} \mathrm{H}$ NMR spectroscopy at 11.74-12.67 ppm corresponding to the proton in $\alpha$ position to the carbene. The carbenic carbon centers appear as doublets at $284.6-290.0 \mathrm{ppm}$ with ${ }^{2} J_{\mathrm{CP}}$ of $96.8-99.8 \mathrm{~Hz}$, in line with previously characterized gold(I) carbenes. . $^{97,107,108,106,115,116,140}$ NBO analyses revealed weak $\pi$-backdonation from the $d_{x z}(A u)$ orbital to the $2 p^{\pi}(C)$ orbital, but significant $C-C(A r) \pi$ bonding.

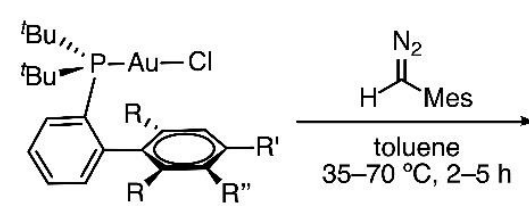

38

$\mathrm{R}=\mathrm{H}$, Me or OMe $\mathrm{R}^{\prime}=\mathrm{H}$, Me or OMe

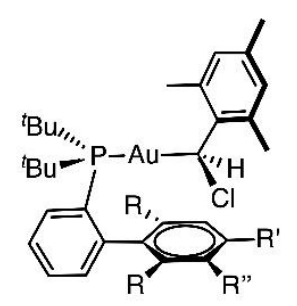

39

$\delta{ }^{13} \mathrm{C}=69.7-73.7$ ppm $\left(J_{\mathrm{CP}}=107.0-109.6 \mathrm{~Hz}\right)$

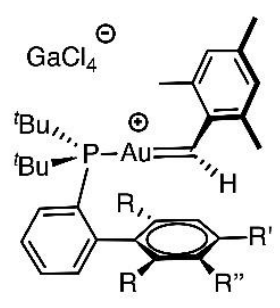

40

$\delta{ }^{13} \mathrm{C}=284.6-290.0 \mathrm{ppm}$ $\left(J_{\mathrm{CP}}=96.8-99.8 \mathrm{~Hz}\right)$

Scheme 15. Synthesis of the chloro(mesityl)methylgold(I) carbenoids 39 and generation of the corresponding monosubstituted gold(I) carbenes $\mathbf{4 0}$.

The monosubstituted gold(I) carbenes $\mathbf{4 0}$ display rich reactivity and undergo typical carbene-type transformations such as cyclopropanation, oxidation, and $\mathrm{C}-\mathrm{H}$ insertion reactions (Scheme 16). For instance, treatment with pyridine $N$-oxide or cyclohexane generated 2,4,6trimethylbenzaldehyde and the $\mathrm{C}-\mathrm{H}$ insertion product, respectively. Small amounts of the $E$ configured alkene dimerization product were observed in both cases. The alkene as well as the corresponding cyclopropane derivative were actually obtained when the gold carbene was warmed up and let to evolve without external reagent. It is nevertheless possible to trap the carbene with alkenes. Mono, di and tri-substituted substrates work well, the corresponding cyclopropanes were all obtained in high yields. 


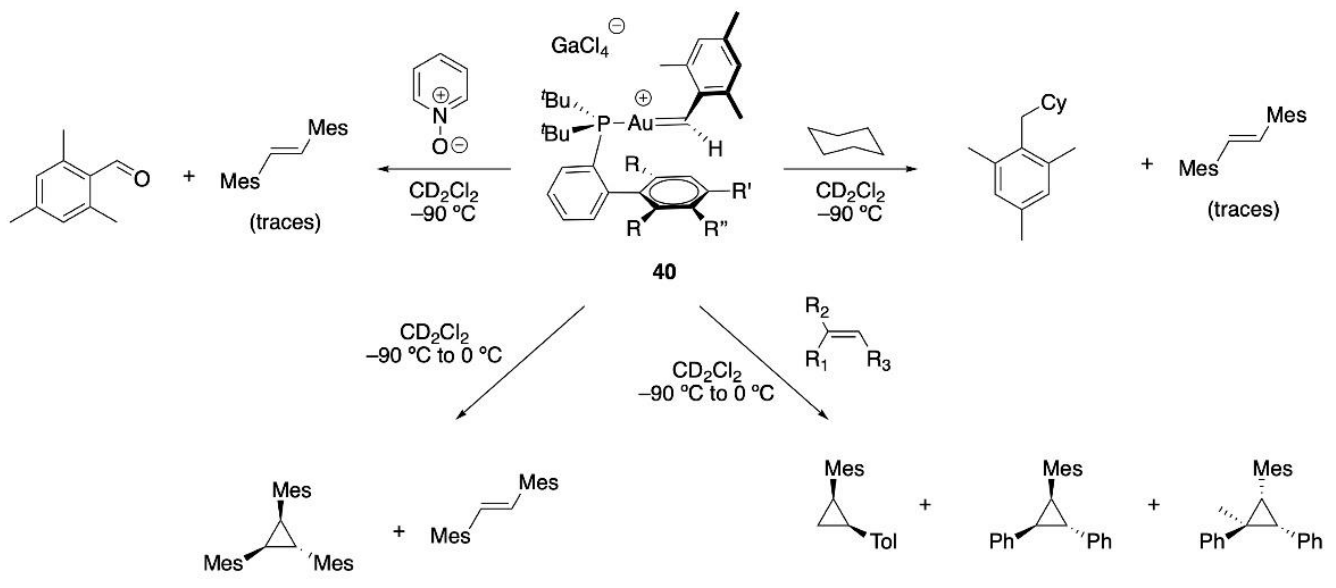

Scheme 16. Reactivity of monosubstituted gold(I) carbenes $\mathbf{4 0 .}$

Recently, Fürstner et al have spectroscopically characterized gold(I) difluorocarbenoid complexes for the first time. ${ }^{147}$ These species were generated by Lewis-acid mediated $\alpha$-fluoride elimination from dicoordinate $\mathrm{L}-\mathrm{Au}-\mathrm{CF}_{3}$ complexes. Reaction of complex 41 with TMSOTf or TMSNTf $_{2}$ resulted in the formation of the gold(I) carbenoid complexes $\mathbf{4 2}$ and $\mathbf{4 3}$, which were only stable below $-50{ }^{\circ} \mathrm{C}$ (Scheme 17). ${ }^{19} \mathrm{~F}$ and ${ }^{31} \mathrm{P}$ NMR spectroscopy showed characteristic signals for one phosphorus center and two fluorine atoms mutually coupled. The carbon atom bonded to gold appeared as a doublet of triplets at $\sim 170 \mathrm{ppm}$ in the ${ }^{13} \mathrm{C}$ NMR spectrum, in line with a carbenoid structure rather than a true "metal carbene" which would resonate at much lower field. ${ }^{148}$ Consistently, ${ }^{19} \mathrm{~F}$ COSY NMR showed cross peaks between the signals of the carbenoid $\mathrm{Au}-\mathrm{CF}_{2}-\mathrm{X}$ and of the OTf group. $\pi$-Donation from the fluorine atoms is insufficient to compensate for the high electrophilicity of the carbon atom, and therefore the weakly coordinating OTf/NTf ${ }_{2}$ counteranions remain covalently bonded. In the presence of TMSOTf, TMSNTf ${ }_{2}$ or $\mathrm{B}\left(\mathrm{C}_{6} \mathrm{~F}_{5}\right)_{3}$, the $\mathrm{L}-\mathrm{Au}-\mathrm{CF}_{3}$ complexes react with stilbenes to give the corresponding difluorocyclopropane. The obtention of the trans cyclopropane trans-44 from both $E$ and Zstilbene, along the formation of some difluoroalkene $\mathbf{4 5}$, argue in favor of a stepwise reaction involving a metala-carbocation as intermediate. 


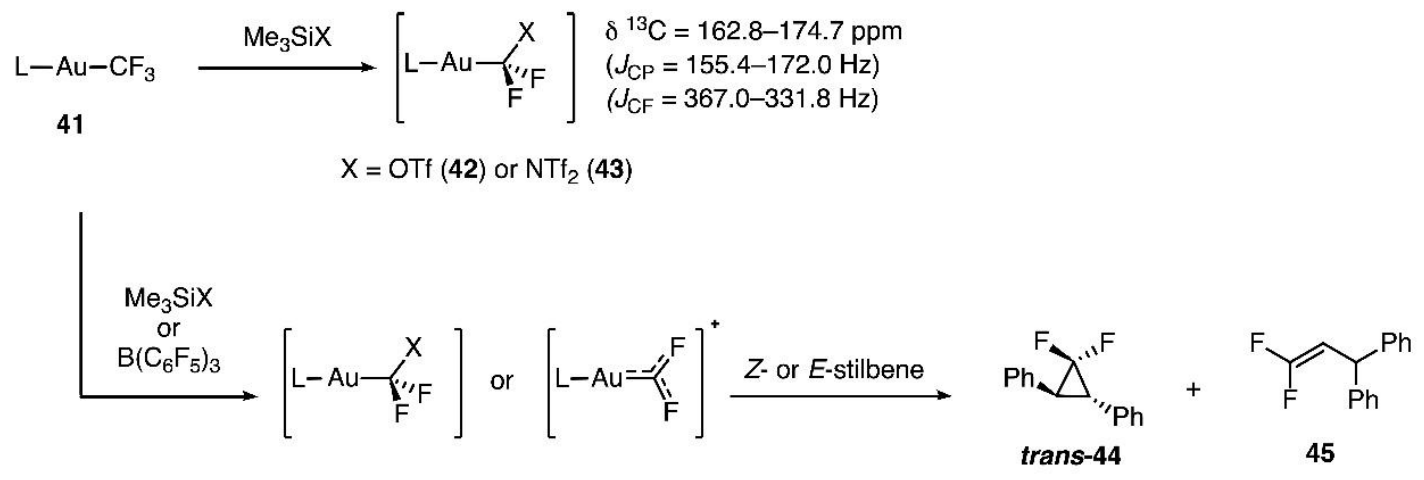

Scheme 17. Generation of gold(I) difluorocarbenoids ( $\mathrm{L}=\mathrm{PPh}_{3}, \mathrm{PCy}_{3}, \mathrm{XPhos},[2,4-$ $\left.(t \mathrm{Bu})_{2} \mathrm{C}_{6} \mathrm{H}_{3} \mathrm{O}\right]_{3} \mathrm{P}$ or $\left.\left(\mathrm{F}_{3} \mathrm{CC}_{6} \mathrm{H}_{4}\right)_{3} \mathrm{P}\right)$ complexes and their reactivity with stilbenes.

Chelating ligands enhance $\mathrm{Au} \rightarrow$ carbene $\pi$-backdonation and are therefore attractive to stabilize both mono-substituted carbenes (with an aryl or an alkyl group), fluorocarbenes and/or fluoroalkyl carbenes at gold(I). $o$-Carboranyl diphosphine derivatives together with other chelating ancillary ligands are certainly to be tested to this end. Besides P-based chelating ligands, rigid and strongly donation $\mathrm{N}^{\wedge} \mathrm{N}$ ligands such of those used for gold(I) $\pi$-complexes are also worthwhile to be explored.

\section{Concluding remarks}

In a few years of time, chelating ligands have proved extremely versatile and powerful in gold(I) chemistry. In particular, $\mathrm{N}^{\wedge} \mathrm{N}, \mathrm{P}^{\wedge} \mathrm{P}$ and $\mathrm{P}^{\wedge} \mathrm{N}$ ligands have enabled to prepare a variety of stable $\pi$ alkene/alkyne and carbene complexes mimicking key transient species involved in important catalytic transformations. The field is still in its infancy and offers many perspectives. The variety of such complexes can certainly be extended further, using other bidentate ligands (including cyclometalated ones) and varying the nature and substitution pattern of the $\pi$-substrate and carbene moiety. Exploring the reactivity of these species is also clearly of high interest. It will for sure advance our knowledge in gold chemistry and open new avenues in gold catalysis.

\section{Acknowledgements}

Financial support from the Centre National de la Recherche Scientifique, the Université de Toulouse and the Agence Nationale de la Recherche is gratefully acknowledged. M. N. thanks the Fonds National Suisse de la Recherche Scientifique for an Early Postdoc Mobility fellowship. 
Special gratitude is expressed to all the coworkers (whose names appear in the references) for their invaluable contribution. K. Miqueu (CNRS/Université de Pau et des Pays de l'Adour, IPREM) is warmly thanked for long-standing, very fruitful and stimulating collaboration. M. Rigoulet is acknowledged for the calculations on the model phosphine and diphosphine complexes.

\footnotetext{
${ }^{1}$ Hashmi ASK, Hutchings GJ. Gold Catalysis. Angew. Chem. Int. Ed. 2006;45(47): 7896-7936. https://doi.org//10.1002/anie.200602454
}

2 Hashmi ASK, Toste FD. Modern Gold Catalyzed Synthesis, Wiley-VCH, 2012. https://doi.org/10.1002/anie.201207733

${ }^{3}$ Carvajal MA, Novoa JJ, Alvarez S. Choice of Coordination Number in $\mathrm{d}^{10}$ Complexes of Group 11 Metals. J. Am. Chem. Soc. 2004;126(5): 1465-1477. https://doi.org/10.1021/ja038416a

${ }^{4}$ Crespo O, Gimeno MC, Laguna A, Jones PG. Two-, Three- and Four-Coordinate Gold(I) Complexes of 1,2-bis(Diphenylphosphino)1,2-Dicarba-closo-dodecarborane. J. Chem. Soc. Dalton Trans. 1992;(10): 1601-1605. https://doi.org/10.1039/DT9920001601

${ }^{5}$ Otsuka S. Chemistry of Platinum and Palladium Compounds of Bulky Phosphines. $J$. Organomet. Chem. 1980;200(1): 191-205. https://doi.org/10.1016/S0022-328X(00)88646-5

${ }^{6}$ Gorin DJ, Toste FD. Relativistic Effects in Homogenous Gold Catalysis. Nature 2007;446: 395403. https://doi.org/10.1038/nature05592

${ }^{7}$ Lauterbach T, Livendahl M, Rosellón A, Espinet P, Echavarren AM. Unlikeliness of Pd-Free Gold(I)-Catalyzed Sonogashira Coupling Reactions. Org. Lett. 2010;12(13): 3006-2009. https://doi.org/10.1021/ol101012n

${ }^{8}$ Livendahl, Goehry C, Maseras F, Echavarren AM. Rationale for the Sluggish Oxidative Addition of Aryl Halides to Au(I). Chem. Commun. 2014;50(13): 1533-1536. https://doi.org/10.1039/C3CC48914K

${ }^{9}$ Teles JH. Oxidative Addition to Gold(I): A New Avenue in Homogeneous Catalysis with Au. Angew. Chem. Int. Ed. 2015;54(19): 5556-5558. https://doi.org/10.1002/anie.201501966

${ }^{10}$ Joost M, Zeineddine A, Estévez L, Mallet-Ladeira S, Miqueu K, Amgoune A, Bourissou D. Facile Oxidative Addition of Aryl Iodides to Gold(I) by Ligand Design: Bending Turns on Reactivity. J. Am. Chem. Soc. 2014;136(42): 14654-14657. https://doi.org/10.1021/ja506978c

${ }^{11}$ Joost M, Estévez L, Miqueu K, Amgoune A, Bourissou D. Oxidative Addition of CarbonCarbon Bonds to Gold. Angew. Chem. Int. Ed. 2015;54(17): 5236-5240. https://doi.org/10.1002/anie.201500458

${ }^{12}$ Zeineddine A, Estévez L, Mallet-Ladeira S, Miqueu K, Amgoune A, Bourissou D. Rational Development of Catalytic $\mathrm{Au}(\mathrm{I}) / \mathrm{Au}(\mathrm{III})$ Arylation Involving Mild Oxidative Addition of Aryl Halides. Nat. Commun. 2018;8: 565. https://doi.org/10.1038/s41467-017-00672-8 
${ }^{13}$ Fernandez I, Wolters LP, Bickelhaupt FM. Controlling the Oxidative Addition of Aryl Halides to $\mathrm{Au}(\mathrm{I})$. J. Compt. Chem. 2014;35(29): 2140-2145. https://doi.org/10.1002/jcc.23734

${ }^{14}$ Huang B, Hu M, Toste FD. Homogenous Gold Redox Chemistry: Organometallics, Catalysis, and Beyond. Trends in Chem. 2020;2(8): 707-720. https://doi.org/10.1016/j.trechm.2020.04.012 ${ }^{15}$ Rodriguez J, Zeineddine A, Sosa-Carrizo ED, Miqueu K, Saffon-Merceron N, Amgoune A, Bourissou D. Catalytic Au(I)/Au(III) Arylation with the Hemilabile MeDalphos Ligand: Unusual Selectivity for Electron-Rich Iodoarenes and Efficient Application to Indoles. Chem. Sci. 2019;10(30): 7183-7192. https://doi.org/10.1039/C9SC01954E

${ }^{16}$ Rodriguez R, Adet N, Saffon-Merceron N, Bourissou D. Au(I)/Au(III)-Catalyzed C-N Coupling. Chem. Commun. 2020;56(1): 94-97. https://doi.org/10.1039/C9CC07666B

${ }^{17}$ Rigoulet M, Thillaye du Boullay O, Amgoune A, Bourissou D. Gold(I)/Gold(III) Catalysis that Merges Oxidative Addition and $\pi$-Alkene Activation. Angew. Chem. Int. Ed. 2020;59(38): 16625-16630. https://doi.org/10.1002/anie.202006074

${ }^{18}$ Akram MO, Das A, Chakravarty I, Patil NT. Ligand-Enabled Gold-Catalyzed C( $\left.\mathrm{sp}^{2}\right)-\mathrm{N}$ Cross Coupling Reactions of Aryl Iodides with Amines. Org. Lett. 2019;21(19):8101-8105. https://doi.org/10.1021/acs.orglett.9b03082

${ }^{19}$ Chintawar CC, Yadav AK, Patil NT. Gold Catalyzed 1,2-Diarylation of Alkenes. Angew. Chem. Int. Ed. 2020;59(29): 11808-11813. https://doi.org/10.1002/anie.202002141

${ }^{20}$ Tathe AG, Chintawar CC, Bhoyare VW, Patil NT. Ligand-Enabled Gold-Catalyzed 1,2Heteroarylation of Alkenes. Chem. Commun. 2020;56(65): 9304-9307. https://doi.org/10.1039/D0CC03707A

${ }^{21}$ Zhang S, Wang C, Ye X, Shi X. Intermolecular Alkene Difunctionalization via Gold-Catalyzed Oxyarylation. Angew. Chem. Int. Ed. 2020;59(46): 20470-20474. https://doi.org/10.1002/anie.202009636

${ }^{22}$ Dyker G. An Eldorado for Homogeneous Catalysis? Angew. Chem. Int. Ed. 2000;39(23): 42374239. https://doi.org/10.1002/1521-3773(20001201)39:23<4237::AID-ANIE4237>3.0.CO;2-A 23 Hashmi ASK. Homogeneous Catalysis. Gold Bull. 2004;37: 51-65. https://doi.org/10.1007/BF03215517

${ }^{24}$ Hoffmann-Röder A, Krause N. The Golden Gate to Catalysis. Org. Biomol. Chem. 2005;3: 387-391. https://doi.org/10.1039/B416516K

${ }^{25}$ Toste FD, Michelet V. Gold Catalysis: An Homogeneous Approach, Imperial College Press, 2014

${ }^{26}$ Slaughter LM. Homogeneous Gold Catalysis, Springer, 2015. https://doi.org/10.1007/978-3319-13722-3

${ }^{27}$ Winter C, Krause N. Gold-Catalyzed Nucleophilic Cyclization of Functionalized Allenes: A Powerful Access to Carbo- and Heterocycles. Chem. Rev. 2011;111(3): 1994-2009. https://doi.org/10.1021/cr1004088 
${ }^{28}$ Chiarucci M, Bandini M. New Developments in Gold-Catalyzed Manipulation of Inactivated Alkenes. Beilstein J. Org. Chem. 2013;9: 2586-2614. https://doi.org/10.3762/bjoc.9.294

${ }^{29}$ Obradors C, Echavarren AM. Intriguing Mechanistic Laberynths in Gold(I) Catalysis. Chem. Commun. 2014;50(1): 16-28. https://doi.org/10.1039/C3CC45518A

${ }^{30}$ Dorel R, Echavarren AM. Gold(I)-Catalyzed Activation of Alkynes for the Construction of Molecular Complexity. Chem. Rev. 2015;115(17): 9028-9072. https://doi.org/10.1021/cr500691k

${ }^{31}$ Halliday CJV, Lynam M. Gold-Alkynyls in Catalysis: Alkyne Activation, Gold Cumulenes and Nuclearity. Dalton Trans. 2016;45(32): 12611-12626. https://doi.org/10.1039/C6DT01641C

${ }^{32}$ Mascareñas JL, Varela I, López F. Allenes and Derivatives in Gold(I)- and Platinum(II)Catalyzed Formal Cycloadditions. Acc. Chem. Res. 2019;52(2): 465-479. https://doi.org/10.1021/acs.accounts.8b00567

${ }^{33}$ Schmidbaur H, Schier A. Gold $\eta^{2}$-Coordination to Unsaturated and Aromatic Hydrocarbons: The Key Step in Gold-Catalyzed Organic Transformations. Organometallics 2010;29(1): 2-23. https://doi.org/10.1021/om900900u

${ }^{34}$ Cinellu MA in Modern Gold Catalyzed Synthesis, Wiley-VCH, 2012: 175-199.

${ }^{35}$ Brooner REM, Widenhoefer RA. Cationic, Two-Coordinate Gold $\pi$ Complexes. Angew. Chem. Int. Ed. 2013;52(45): 11714-11724. https://doi.org/10.1002/anie.201303468

${ }^{36}$ Jones AC. Gold $\pi$-Complexes as Model Intermediates in Gold Catalysis. Top. Curr. Chem. 2015;357: 133-166. https://doi.org/10.1007/128_2014_593

${ }^{37}$ Blons C, Amgoune A, Bourissou D. Gold(III) $\pi$ Complexes. Dalton Trans. 2018;47(31): 10388-10393. https://doi.org/10.1039/C8DT01457D

38 Zeise WC, Von der Wirkung zwischen Platinchlorid und Alkohol, und von den dabei entstehenden neuen Substanzen. Ann. Phys Chem. 1831;97(4): 497-541. https://doi.org/10.1002/andp.18310970402

${ }^{39}$ Dell'Amico DB, Calderazzo F, Dantona R, Straehle J, Weiss H. Olefin Complexes of Gold(I) by Carbonyl Displacement from Carbonylgold(I) Chloride. Organometallics 1987;6(6): 12071210. https://doi.org/10.1021/om00149a014

40 Davila RM, Staples RJ, Fackler Jr JP. Synthesis and Structural Characterization of $\mathrm{Au}_{4}(\mathrm{MNT})(\mathrm{dppe})_{2}(\mathrm{Cl})_{2} \cdot 1 / 4 \mathrm{CH}_{2} \mathrm{Cl}_{2}(\mathrm{MNT}=1$,2-Dicyanoetheen-1,2-dithiolate-S,S'; dppe $=$ cisBis(diphenylphosphino)ethylene): A Gold(I) Metal-Olefin Complex in Which the Olefin Orientation Relative to the Coordination Plane Involving the Metal Is Defined. Organometallics 1994;13(2): 418-420. https://doi.org/10.1021/om00014a007

${ }^{41}$ Mingos DMP, Yau J, Menzer S, Williams DJ. A Gold(I) [2]Catene. Angew. Chem. Int. Ed. 1995;34(17): 1894-1895. https://doi.org/10.1002/anie.199518941 
${ }^{42}$ Lang H, Kohler K, Zsolnai L. Unusual Coordination Mode of Organogold(I) Compounds: Trigonal-Planar Complexation of Gold(I) Centers by Alkynes. Chem. Commun. 1996;17: 20432044. https://doi.org/10.1039/CC9960002043

${ }^{43}$ Köhler K, Silverio SJ, Hyla-Krypsin I, Gleiter R, Zsolnai L, Driess A, Huttner G, Lang H. Trigonal-Planar-Coordinated Organogold(I) Complexes Stabilized by Organometallic 1,4Diynes: Reaction Behavior Structure, and Bonding. Organometallics 1997;16(23): 4970-497. https://doi.org/10.1021/om970302i

${ }^{44}$ Schulte P, Behrens U. Strong Coordination of Cycloheptynes by Gold(I) Chloride: Synthesis and Structure of Two Complexes of the Type [(alkyne)AuCl] Chem. Commun. 1998;16: 16331634. https://doi.org/10.1039/A803791D

${ }^{45}$ McIntosh DF, Ozin GA. Direct Synthesis Using Gold Atoms: Synthesis, Infrared and Ultraviolet-Visible Spectra and Molecular Orbital Investigation of Monoethylene Gold(0), $\left(\mathrm{C}_{2} \mathrm{H}_{4}\right) \mathrm{Au} . \quad$ J. Organomet. Chem. 197;121(1): 127-136. https://doi.org/10.1016/S0022328X(00)85515-1

${ }^{46}$ McIntosh DF, Ozin Ga, Messmer RP. Optical and SCF- $\mathrm{X}_{\mathrm{a}}-\mathrm{SW}$ Investigations of $\mathrm{M}\left(\pi-\mathrm{C}_{2} \mathrm{H}_{4}\right)$, Where $\mathrm{M}=\mathrm{Cu}, \mathrm{Ag}$, and Au. Inorg. Chem. 1980;19(11): 3321-3327. https://doi.org/10.1021/ic50213a023

${ }^{47}$ Kasai PH. Acetylene and Ethylene Complexes of Gold Atoms: Matrix Isolation ESR Study. $J$. Am. Chem. Soc. 1983;105(22): 6704-6710. https://doi.org/10.1021/ja00360a026

${ }^{48}$ Kasai PH. Propylene Complexes of Copper, Silver and Gold Atoms: Matrix Isolation ESR Study. J. Am. Chem. Soc. 1984;106(11): 3069-2075. https://doi.org/10.1021/ja00323a001

49 Kasai PH. Bis(ethylene)gold(0) and Bis(propylene)gold(0) Complexes: Gold Nuclear Hyperfine and Quadrupole Coupling Tensors. J. Phys. Chem. 1988;92(8): 2161-2165. https://doi.org/10.1021/j100319a016

${ }^{50}$ Nicolas G, Spiegelmann F. Theoretical Study of Ethylene-Noble metal Complexes. J. Am. Chem. Soc. 1999;112(14): 5410-5419. https://doi.org/10.1021/ja00170a003

${ }^{51}$ Bond GC, Serman PA. Gold Catalysis for Olefin Hydrogenation. Gold Bull. 1973;6: 102-105. https://doi.org/10.1007/BF03215018

${ }^{52}$ Savjani N, Rosca D, Schormann M, Bochmann M. Gold(III) Olefin Complexes. Angew. Chem. Int. Ed 2013;52(3): 874-877. https://doi.org/10.1002/anie.201208356

${ }^{53}$ Langseth E, Scheuermann ML, Balcells D, Kaminsky W, Goldberg KI, Eisenstein O, Heyn RH, Tilset M. Generation and Structural Characterization of a Gold(III) Alkene Complex. Angew. Chem. Int. Ed. 2013;52(6): 1660-1663. https://doi.org/10.1002/anie.201209140

${ }^{54}$ Rocchigiani L, Fernandez-Cestau J, Agonigi G, Chambrier I, Budzelaar PHM, Bochmann M. Gold(III) Alkyne Complexes: Bonding and Reaction Pathways. Angew. Chem. Int. Ed. 2017;56(44): 13861-13865. https://doi.org/10.1002/anie.201708640 
${ }^{55}$ Rekhroukh F, Blons C, Estévez L, Mallet-Ladeira S, Miqueu K, Amgoune A, Bourissou D. Gold(III)-Arene Complexes by Insertion of Olefins into Gold-Aryl Bonds. Chem. Sci. 2017;8(6): 4539-4545. https://doi.org/10.1039/C7SC00145B

${ }^{56}$ Rodríguez J, Szalóki G, Sosa-Carrizo ED, Saffon-Merceron N, Miqueu K, Bourissou D. Gold(III) $\pi$-Allyl Complexes. Angew. Chem. Int. Ed. 2020;59(4): 1511-1515. https://doi.org/10.1002/anie.201912314

${ }^{57}$ Holmsen MSM, Nova A, Oien-Odegaard S, Heyn RH, Tilset M. A Highly Asymmetric Gold(III) $\eta^{3}$-Allyl Complex. Angew. Chem. Int. Ed. 2020;59(4): 1516-1520. https://doi.org/10.1002/anie.201912315

${ }^{58}$ Zuccaccia D, Belpassi L, Tarantelli F, Macchioni A. Ion Pairing in Cationic Olefin-Gold(I) Complexes. J. Am. Chem. Soc. 2009;131(9): 3170-3171. https://doi.org/10.1021/ja809998y

${ }^{59}$ Brown TJ, Dickens MG, Widenhoefer RA. Synthesis, X-Ray Crystal Structures, and Solution Behavior of Monomeric, Cationic, Two-Coordinate Gold(I) $\pi$-Alkene Complexes. J. Am. Chem. Soc. 2009;131(18): 6350-6351. https://doi.org/10.1021/ja9015827

${ }^{60}$ de Frémont P, Marion N, Nolan SP. Cationic NHC-gold(I) Complexes: Synthesis, Isolation, and Catalytic Activity. J. Organomet. Chem. 2009;694(4): 441-560. https://doi.org/10.1016/j.jorganchem.2008.10.047

${ }^{61}$ Hooper TN, Green M, McGrady JE, Patel JR, Russell CA. Synthesis and Structural Characterisation of Stable Cationic Gold(I) Alkene Complexes. Chem. Commun. 2009;(26): 3877-3879. https://doi.org/10.1039/B908109G

${ }^{62}$ Brown TJ, Dichens MG, Widenhoefer RA. Synthesis and X-Ray Crystal Structures of Cationic, Two-coordinate Gold(I) $\pi$-Alkene Complexes that Contain a Sterically Hindered $o$ Biphenylphosphine ligand. Chem. Comunn. 2009;(42): 6451-6453. https://doi.org/10.1039/B914632F

${ }^{63}$ Motloch P, Blahut J, Cisorova I, Roithova J. X-Ray Characterization of TriphenylphosphineGold(I) olefin $\pi$-Complexes and the Revision of their Stability in Solution. J. Organomet. Chem. 2017;848: 114-117. https://doi.org/10.1016/j.jorganchem.2017.07.011

${ }^{64}$ Griebel C, Hodges DD, Yager BR, Liu FL, Zhou W, Makaravage KJ, Zhu Y, Norman SG, Lan R, Day CS, Jones AC. Bisphenyl Phosphines: Structure and Synthesis of Gold(I) Alkene $\pi$ Complexes with Variable Phosphine Donicity and Enhanced Stability. Organometallics 2020;39(14): 2664-2671. https://doi.org/10.1021/acs.organomet.0c00278

${ }^{65}$ Cinellu MA, Minghetti G, Stoccoro S, Zucca A, Manassero M. Reacion of Gold(III) oxo Complexes with Alkenes. Synthesis of Unprecedented Gold Alkene Complexes, $[\mathrm{Au}(N, N)($ alkene $)]\left[\mathrm{PF}_{6}\right]$. Crystal Structure of $\left[\mathrm{Au}\left(\right.\right.$ bipy $\left.\left.^{\mathrm{ip}}\right)\left(\eta^{2}-\mathrm{CH}_{2}=\mathrm{CHPh}\right)\right]\left[\mathrm{PF}_{6}\right]$ (bipy ${ }^{\text {ip }}=6$ ispropyl-2,2'bipyridine). Chem. Commun. 2004;(14):1618-1619. https://doi.org/10.1039/B404890C 
${ }^{66}$ Cinellu MA, Minghetti G, Cocco F, Stoccoro S, Zucca A, Manassero M, Arca M. Synthesis and Properties of Gold Alkene Complexes. Crystal Sructure of $\left[\mathrm{Au}\left(\mathrm{bipy}^{\mathrm{oXyl}}\right)\left(\eta^{2}-\right.\right.$ $\left.\left.\mathrm{CH}_{2}=\mathrm{CHPh}\right)\right]\left(\mathrm{PF}_{6}\right)$ and DFT Calculations on the Model Cation [Au(bipy) $\left.)\left(\eta^{2}-\mathrm{CH}_{2}=\mathrm{CHPh}\right)\right]^{+}$. Dalton Trans. 2006;(48): 5703-5716. https://doi.org/10.1039/B610657A

${ }^{67}$ Cinellu MA, Minghetti G, Cocco F, Stoccoro S, Zucca A, Manassero M. Reactions of Gold(III) Oxo Complexes with Cyclic Alkenes. Angew. Chem. Int. Ed. 2005;44(42): 6892-6895. https://doi.org/10.1002/anie.200501754

${ }^{68}$ Dias HVR, Wu J. Structurally Characterized Coinage-Metal-Ethylene Complexes. Eur. J. Inorg. Chem. 2018;(12): 2113. https://doi.org/10.1002/ejic.200800231

69 Dias HVR, Wu J. Thermally Stable Gold(I) Ethylene Adducts: $\left[\left(\mathrm{HB}\left\{3,5\left(\mathrm{CF}_{3}\right)_{2} \mathrm{Pz}\right\}_{3} \mathrm{Au}\left(\mathrm{CH}_{2}=\mathrm{CH}_{2}\right)\right]\right.$. Angew. Chem. Int. Ed. 2007;46(41): 7814-7816. https://doi.org/10.1002/anie.200703328

${ }^{70}$ Dias HVR, Wu J. Structurally Similar, thermally Stable Copper(I), Silver(I), and Gold(I) Ethylene Complexes Supported by a Fluorinated Scorpionate. Organometallics 2012;31(4): 1511-1517. https://doi.org/10.1021/om201185v

${ }^{71}$ Ridlen SG, Wu, J, Kulkarni NV, Dias HVR. Isolable Ethylene Complexes of Copper(I), Silver(I), and Gold(I) Supported by Fluorinated Scorpionates $\left[\mathrm{HB}\left\{3-\left(\mathrm{CF}_{3}\right), 5-\left(\mathrm{CH}_{3}\right) \mathrm{Pz}\right\}_{3}\right]^{-}$and $\left[\mathrm{HB}\left\{3-\left(\mathrm{CF}_{3}\right), 5-(\mathrm{Ph}) \mathrm{Pz}\right\}_{3}\right]^{-}$. Eur. J. Inorg. Chem. 2016(15-16): 2573-2580. https://doi.org/10.1002/ejic.201501365

${ }^{72}$ Nes GJH, Vos A. Single-Crystal Structures and Electron Density Distributions of Ethane, Ethylene and Acetylene. III. Single-Crystal X-Ray Structure Determination of Ethylene at $85 \mathrm{~K}$. Act. Crystalogr. B 1979;35(11): 2593-2601. https://doi.org/10.1107/S0567740879009961

${ }^{73}$ Krossing I, Reisinger A. A Stable Salt of the Tris(ethene)silver Cation: Structure and Characterization of $\left[\mathrm{Ag}\left(\eta_{2}-\mathrm{C}_{2} \mathrm{H}_{4}\right)_{3}\right]^{+}\left[\mathrm{Al}\left\{\mathrm{OC}\left(\mathrm{CF}_{3}\right)_{3}\right\}_{4}\right]^{-}$. Angew. Chem. Int. Ed. 2003;42(46): 5725-5728. https://doi.org/10.1002/anie.200352080

74 Batsanov SS. Van der Waals Radii of Elements. Inorg. Mater. 2001;37: 871-885. https://doi.org/10.1023/A:1011625728803

$75 \mathrm{Wu}$ J, Noonikara-Poyil A, Muñoz-Castro A, Dias HVR. Gold(I) Ethylene Complexes Supported by Electron-rich Scorpionates. Chem. Commun. 2021;57(8): 978-981. https://doi.org/10.1039/D0CC07717H

${ }^{76}$ Flores JA, Dias HVR. Gold(I) Ethylene and Copper(I) Ethylene Complexes Supported by a Polyhalogenated Triazapentadienyl Ligand. Inorg. Chem. 2008;47(11): 4448-4450. https://doi.org/10.1021/ic800373u

${ }^{77}$ Dias HVR, Flores JA, Wu J, Kroll P. Monomeric Copper(I), Silver(I), and Gold(I) Alkyne Complexes and the Coinage Metal Family Group Trends. J. Am. Chem. Soc. 2009;131(31): 11249-11255. https://doi.org/10.1021/ja904232v 
${ }^{78}$ Hooper TN, Green M, Russell CA. Cationic Au(I) Alkyne Complexes: Synthesis, Structure and Reactivity. Chem. Commun. 2010,46(13): 2313-2315. https://doi.org/10.1039/B923900F

${ }^{79}$ Zuccaccia D, Belpassi L, Rocchigiani L, Tarantelli F, Macchioni A. A Phosphine Gold(I) $\pi$ Alkyne Complex: Tuning the Metal-Alkyne Bond Character and Counterion Position by the Choice of the Ancillary Ligand. Inorg. Chem. 2010;49(7): 3080-3082. https://doi.org/10.1021/ic100093n

${ }^{80}$ Cationic Gold(I) $\pi$-Complexes of Terminal Alkynes and Their Conversion to Dinuclear $\sigma, \pi$ Acetylide Complexes. $\quad$ Organometallics 2011;30(21): 6003-6009. https://doi.org/10.1021/om200840g

${ }^{81}$ Ciancaleoni G, Biasiolo L, Bistoni G, Macchioni A, Tarantelli F, Zuccaccia D, Belpassi L. NHC-Gold-Alkyne Complexes: Influence of the Carbene Backbone on the Ion Pair Structure. Organometallics 2013;32(15): 4444-4447. https://doi.org/10.1021/om4005912

${ }^{82}$ Klimovica K, Krischbaum K, Daugulis O. Synthesis and Properties of "Sandwich" DiimineCoinage Metal Ethylene Complexes. Organometallics 2016;35(17): 2938-2943. https://doi.org/10.1021/acs.organomet.6b00487

${ }^{83}$ Dias HVR, Fianchini M, Cundari TR, Campana CF. Synthesis and Characterization of the Gold(I) Tris(ethylene) Complex [ $\left.\mathrm{Au}\left(\mathrm{C}_{2} \mathrm{H}_{4}\right)_{3}\right]\left[\mathrm{SbF}_{6}\right]$. Angew. Chem. Int. Ed. 2007;47(3): 556-559. https://doi.org/10.1002/anie.200703515

${ }^{84}$ Harper MJ, Arthur CJ, Crosby J, Emmett EJ, Falconer RL, Fensham-Smith AJ, Gates PJ, Leman T, McGrady JE, Bower J, Russell CA. Oxidative Addition, Transmetalation, and Reductive Elimination at a 2,2'-Bipyridyl-Ligated Gold Center. J. Am. Chem. Soc. 2018;140(12): 4440-4445. https://doi.org/10.1021/jacs.8b01411

${ }^{85}$ Cadge JA, Sparkes HA, Bower JF, Russel CA. Oxidative Addition of Alkenyl and Alkynyl Iodides to $\mathrm{a} \mathrm{Au}^{\mathrm{I}}$ Complex. Angew. Chem. Int. Ed. 2020;59(16): 6617-6621. https://doi.org/10.1002/anie.202000473

${ }^{86}$ Brand JP, Charpentier J, Waser J. Direct Alkynylation of Indole and Pyrrole Heterocycles. Angew. Chem. Int. Ed. 2009;48(49): 9346-9349. https://doi.org/10.1002/anie.200905419

${ }^{87}$ Brand JP, Waser J. Direct Alkynylation of Thiophenes: Cooperative Activation of TIPS-EBX with Gold and Bronsted Acids. Angew. Chem. Int. Ed. 2010;49(40): 7304-7307. https://doi.org/10.1002/anie.201003179

${ }^{88} \mathrm{Li}$ Y, Brand JP, Waser J. Gold-Catalyzed Regioselective Synthesis of 2- and 3-Alkynyl Furans. Angew. Chem. Int. Ed. 2013;52(26): 6743-6747. https://doi.org/10.1002/anie.201302210

${ }^{89}$ Peng H, Xi Y, Ronaghi N, Dong B, Akhmedov NG, Shi X. Gold-Catalyzed Oxidative CrossCoupling of Terminal Alkynes: Selective Synthesis of Unsymmetrical 1,3-Diynes. J. Am. Chem. Soc. 2014;136(38): 13174-13177. https://doi.org/10.1021/ja5078365

${ }^{90}$ Cai R, Lu M, Aguilera EY, Xi Y, Akhmedov NG, Petersen JL, Chen H, Shi X. Ligand-Assisted Gold-Catalyzed Cross-Coupling with Arylazonium Salts: Redox Gold Catalysis without an 
External Oxidant. Angew. Chem. Int. Ed. 2015;54(30): 8772-8776. https://doi.org/10.1002/anie.201503546

${ }^{91}$ Li X, Xie X, Sun N, Liu Y. Gold-Catalyzed Cadiot-Chodkiewicz-type Cross-Coupling of Terminal Alkynes with Alkynyl Hypervalent Iodine Reagents: Highly Selective Synthesis of Unsymmetrical 1,3-Diynes. Angew. Chem. Int. Ed. 2017;56(24): 6994-6998. https://doi.org/10.1002/anie.201702833

${ }^{92}$ Yang Y, Antoni P, Zimmer M, Sekine K, Mulks FF, Hu L, Zhang L, Rudolph M, Rominger F, Hashmi ASK. Dual Gold/Silver Catalysis Involving Alkynylgold(III) Intermediates Formed by Oxidative Addition and Silver-Catalyzed $\mathrm{C}-\mathrm{H}$ Activation for the Direct Alkynylation of Cyclopropenes. Angew. Chem. Int. Ed. 2019;58(15): 5129-5133. https://doi.org/10.1002/anie.201812577

${ }^{93}$ Yang Y, Eberle L, Mulks FF, Wunsch JF, Zimmer M, Rominger F, Rudolph M, Hashmi ASK. Trans Influence of Ligands on the Oxidation of Gold(I) Complexes. J. Am. Chem. Soc 2019;141(43): 17414-17420. https://doi.org/10.1021/jacs.9b09363

${ }^{94}$ Cinellu MA, Arca M, Ortu F, Stoccoro S, Zucca A, Pintus A, Maiore L. Structural, Theoretical and Spectroscopic Characterisation of a Series of Novel Gold(I)-Norbornene Complexes Supported by Phenantrolines: Effects of the Supporting Ligand. Eur. J. Inorg. Chem. 2019;2019(44): 4784-4795. https://doi.org/10.1002/ejic.201901116

${ }^{95}$ Navarro M, Toledo A, Joost M, Amgoune A, Mallet-Ladeira S, Bourissou D. $\pi$-Complexes of $\mathrm{P}^{\wedge} \mathrm{P}$ and $\mathrm{P}^{\wedge} \mathrm{N}$ Chelated Gold(I). Chem. Commun. 2019;55(55): 7974-7977. https://doi.org/10.1039/C9CC04266K

${ }^{96}$ Navarro M, Toledo A, Mallet-Ladeira S, Sosa-Carrizo ED, Miqueu K, Bourissou D. Versatility and Adaptative Behaviour of the $\mathrm{P}^{\wedge} \mathrm{N}$ Chelating Ligand MeDalphos within Gold(I) $\pi$ Complexes. Chem. Sci. 2020;11(10): 2750-2758. https://doi.org/10.1039/C9SC06398F

${ }^{97}$ Joost M, Estévez L, Mallet-Ladeira S, Miqueu K, Amgoune A, Bourissou D. Enhanced $\pi$ Backdonation from Gold(I): Isolation of Original Carbonyl and Carbene Complexes. Angew. Chem. Int. Ed. 2014;53(52): 14512-14516. https://doi.org/10.1002/anie.201407684

${ }^{98}$ Zeineddine A, Rekhroukh F, Sosa-Carrizo ED, Mallet-Ladeira S, Miqueu K, Amgoune A, Bourissou D. Isolation of a Reactive Tricoordinate $\alpha$-Oxo Gold Carbene Complex. Angew. Chem. Int. Ed. 2018;57(5): 1306-1310. https://doi.org/10.1002/anie.201711647

${ }^{99}$ Fürstner A, Alcarazo M, Goddard R, Lehmann CW. Coordination Chemistry of Ene-1,1diamines and a Prototype "Carbodicarbene". Angew. Chem. Int. Ed. 2008;47(17): 3210-3214. https://doi.org/10.1002/anie.200705798

${ }^{100}$ Sanguramath RA, Hooper TN, Butts CP, Green M, McGrady JE, Russell CA. The Interaction of Gold(I) Cations with 1,3-Dienes. Angew. Chem. Int. Ed. 2011;50(33): 7592-7595. https://doi.org/10.1002/anie.201102750 
${ }^{101}$ Zhu Y, Day CS, Jones AC. Synthesis and Structure of Cationic Phosphine Gold(I) Enol Ether Complexes. Organometallics 2012;31(21): 7332-7335. https://doi.org/10.1021/om300893q

102 Sriram M, Zhu Y, Camp AM, Day CS, Jones AC. Structure and Dynamic Behavior of Phosphine Gold(I)-Coordinated Enamines: Characterization of $\alpha$-Metalated Iminium Ions. Organometallics 2014;33(16): 4157-4164. https://doi.org/10.1021/om500670z

${ }^{103}$ Zhdanko A, Maier M. Mechanistic Study of Gold(I)-Catalyzed Hydroamination of Alkynes: Outer or Inner Sphere Mechanism? Angew. Chem. Int. Ed. 2014;53(30): 7760-7764. https://doi.org/10.1002/anie.201402557

${ }^{104}$ Aumann R, Fischer EO. Neue Gold-Carbene-Komplexe durch Carbenübertragung. Chem. Ber. 1981;114(5): 1853-1857. https://doi.org/10.1002/cber.19811140523

105 For X-ray diffraction analysis of the $\mathrm{Cl}-\mathrm{Au}=\mathrm{C}\left(\mathrm{NMe}_{2}\right) \mathrm{Ph}$ complex, see: Schubert $\mathrm{U}$, Ackermann K, Aumann Chloro[dimethylamino(phenyl)carbene]gold(I), $\mathrm{ClAuC}\left(\mathrm{C}_{6} \mathrm{H}_{5}\right) \mathrm{N}_{(}\left(\mathrm{CH}_{3}\right)_{2}$. R. Cryst. Struct. Commun. 1982;11(2): 591-594.

106 Seidel G, Fürstner A. Structure of a Reactive Gold Carbenoid. Angew. Chem. Int. Ed. 2014;53(19): 4807-4811. https://doi.org/10.1002/anie.201402080

${ }^{107}$ Fañanas-Mastral M, Aznar F. Carbene Transfer Reaction from Chromium(0) to Gold(I): Synthesis and Reactivity of New Fischer-Type Gold(I) Alkenyl Carbene Complexes. Organometallics 2009;28(3): 666-668. https://doi.org/10.1021/om801146z

${ }^{108}$ Brooner REM, Widenhoefer RA, Experimental Evaluation of the Electron Donor Ability of a Gold Phosphine Fragment in a Gold Carbene Complex. Chem. Commun. 2014;50(19): 24202423. https://doi.org/10.1039/C3CC48869A

109 Minghetti G, Bonati F. Bis(Carbene) Complexes of Gold(I) and Gold(III). J. Organomet. Chem. 1973;54: C62-C63. https://doi.org/10.1016/S0022-328X(00)84984-0

${ }^{110}$ Raubenheimer HG, Cronje S. Carbene Complexes of Gold: Preparation, Medical Application and Bonding. Chem. Soc. Rev. 2008;37(9): 1998-2011. https://doi.org/10.1039/B708636A

${ }^{111}$ Mora M, Gimeno MC, Visbal R. Recent Advances in Gold-NHC Complexes with Biological Properties. Chem. Soc. Rev. 2018;48(2): 447-462. https://doi.org/10.1039/C8CS00570B

112 Visbal R, Gimeno MC. N-Heterocylic Carbene Metal Complexes: Photoluminescence and Applications. Chem. Soc. Rev. 2014;43(10): 35513574. https://doi.org/10.1039/C3CS60466G

${ }^{113}$ Marion N, Nolan SP. N-Heterocylic Carbenes in Gold Catalysis. Chem. Soc. Rev. 2008;37(9): 1776-1782. https://doi.org/10.1039/B711132K

114 Brooner REM, Brown TJ, Widenhoefer RA. Direct Observation of a Cationic Gold(I)Bicyclo[3.2.0]hept-1(7)-ene Complex Generated in the Cycloisomerization of a 7-Phenyl-1,6enyne. Angew. Chem. Int. Ed. 2013;52(24): 6250-6261. https://doi.org/10.1002/anie.201301640 115 Harris RJ, Widenhoefer RA. Synthesis, Structure, and Reactivity of a Gold Carbenoid Complex that Lacks Heteroatom Stabilization. Angew. Chem. Int. Ed. 2014;53(35): 9369-9371. https://doi.org/10.1002/anie.201404882 
${ }^{116}$ Hussong MW, Rominger F, Krämer P, Straub BF. Isolation of a Non-Heteroatom-Stabilized Gold-Carbene Complex. Angew. Chem. Int. Ed. 2014;53(35): 9372-9375. https://doi.org/10.1002/anie.201404032

117 Qian D, Zhang J. Gold-Catalyzed Cyclopropanation Reactions Using a Carbenoid Precursor Toolbox. Chem. Soc Rev. 2015;44(3): 677-698. https://doi.org/10.1039/C4CS00304G

${ }^{118}$ Liu L, Zhang J. Gold-Catalyzed Transformations of $\alpha$-Diazocarbonyl Compounds: Selectivity and Diversity. Chem. Soc. Rev. 2016;45(3):506-516. https://doi.org/10.1039/C5CS00821B

${ }^{119}$ Fructos MR, Díaz-Requejo MM, Pérez PJ. Gold and Diazo Reagents: a Fruitful Tool for Developing Molecular Complexity. Chem. Commun. 2016;46(52):7326-7335. https://doi.org/10.1039/C6CC01958G

${ }^{120}$ Fructos MR, Belderrain TR, de Frémont P, Scott NM, Nolan SP, Díaz-Requejo MM, Pérez PJ. A Gold Catalyst for Carbene-Transfer Reactions from Ethyl Diazoacetate. Angew. Chem. Int. Ed. 2005;44(33): 5285-5288. https://doi.org/10.1002/anie.200501056

121 de Frémont P, Stevens ED, Fructos MR, Díaz-Requejo MM, Pérez PJ, Nolan SP. Synthesis, Isolation and Characterization of a Cationic Gold(I) $N$-Heterocyclic Carbene (NHC) Complexes. Chem. Commun. 2006;(19): 2045-2047. https://doi.org/10.1039/B601547F

${ }^{122}$ Fructos MR, de Frémont P, Nolan SP, Díaz-Requejo MM, Pérez PJ. Alkene Carbon-Hydrogen Bond Functionalization with $(\mathrm{NHC}) \mathrm{MCl}$ Precatalysts $(\mathrm{M}=\mathrm{Cu}, \mathrm{Au} ; \mathrm{NHC}=\mathrm{N}$-Heterocylic Carbene). Organometallics 2006;25(9)2247-2241. https://doi.org/10.1021/om0507474

${ }^{123}$ Barluenga J, Lonzi G, Tomás M, López LA. Reactivity of Stabilized Vinyl Diazo Derivatives toward Unsaturated Hydrocarbons: Regioselective Gold-Catalyzed Carbon-Carbon Bond Formation. Chem. Eur. J. 2013;19(5): 1573-1576. https://doi.org/10.1002/chem.201203217 ${ }^{124}$ López E, Lonzi G, López LA. Gold-Catalyzed C-H Bond Functionalization of Metallocenes: Synthesis of Densely Functionalized Ferrocene Derivatives. Organometallics 2014;33(21): 5924-5927. https://doi.org/10.1021/om500638t

${ }^{125}$ Yu Z, Ma B, Chen M, Wu H-H, Liu L, Zhang J. Highly Site-Selective Direct C-H Bond Functionalization of Phenols with $\alpha$-Aryl- $\alpha$-diazoacetates and Diazooxindoles via Gold Catalysis. J. Am. Chem. Soc. 2014;136(19): 6904-6907. https://doi.org/10.1021/ja503163k

126 Pagar VV, Liu R-S. Gold-Catalyzed Cycloaddition Reactions of Ethyl Diazoacetate, Nitrosoarenes, and Vinyldiazo Carbonyl Compounds Synthesis of Isoxazolidine and Benzo[b]azepine Derivatives. Angew. Chem. Int. Ed. 2015;54(16): 4923-4926. https://doi.org/10.1002/anie.201500340

127 Zhang D, Xu G, Ding D, Zhu C, Li J, Sun J. Gold(I)-Catalyzed Diazo Coupling: Strategy towards Alkene Formation and Tandem Benzannulation. Angew. Chem. Int. Ed. 2014;53(41): 11070-11074. https://doi.org/10.1002/anie.201406712 
${ }^{128}$ Xu G, Zhu C, Gu W, Li J, Sun J. Gold(I)-Catalyzed Diazo Cross-Coupling: A Selective and Ligand-Controlled Denitrogenation/Cyclization Cascade. Angew. Chem. Int. Ed. 2015;54(3): 883-887. https://doi.org/10.1002/anie.201409845

${ }^{129}$ Schulz J, Jasiková L, Skríba A, Roithová K. Role of Gold(I) $\alpha$-Oxo Carbenes in the Oxidation Reactions of Alkynes Catalyzed by Gold(I) Complexes. J. Am. Chem. Soc. 2014;136(32): 1151311523. https://doi.org/10.1021/ja505945d

${ }^{130}$ Schulz J, Jasik J, Gray A, Roithová J. Formation of Oxazoles from Elusive Gold(I) $\alpha$ Oxocarbenes: A Mechanistic Study. Chem. Eur. J. 2016;22(28): 9827-9834. https://doi.org/10.1002/chem.201601634

${ }^{131} \alpha$-Oxo copper(I) carbene complex were earlier authenticated, see: Straub BF, Hofmann P. Copper(I) Carbenes: The Synthesis of Active Intermediates in Copper-Catalyzed Cyclopropanation. Angew. Chem. Int. Ed .2001;40(7): 1288-1290. https://doi.org/10.1002/15213773(20010401)40:7<1288::AID-ANIE1288>3.0.CO;2-6

${ }^{132}$ Luo Y, Ji K, Li Y, Zhang L. Tempering the Reactivities of Postulated $\alpha$-Oxo Gold Carbenes Using Bidentate Ligands: Implication of Tricoordinated Gold Intermediates and the Development of an Expedient Bimolecular Assembly of 2,4-Disubstituted Oxazoles. J. Am. Chem. Soc. 2012;134(42): 17412-17415. https://doi.org/10.1021/ja307948m

${ }^{133}$ Wu G, Zheng R, Nelson J. Zhang L. One-Step Synthesis of Methanesulfonyloxymethyl Ketones via Gold-Catalyzed Oxidation of Terminal Alkynes. A Combination of Ligand and Counter Anion Enales High Efficiency and a One-Pot Synthesis of 2,4-Disubstituted Thiazoles. Adv. Synth. Catal. 2014;356(6): 1229-1234. https://doi.org/10.1002/adsc.201300855

${ }^{134}$ Ji K, D’Souza B, Nelson J. Zhang L. Gold-Catalyzed Oxidation of Propargylic Ethers with Internal $\mathrm{C}-\mathrm{C}$ Triple Bonds: Impressive Regioselectivity Enabled by Inductive Effect. $J$. Organomet. Chem. 2014;770: 142-145. https://doi.org/10.1016/j.jorganchem.2014.08.005

${ }^{135}$ Li J, Ji K, Zheng R, Nelson J, Zhang L. Expanding the Horizon of Intermolecular Trapping of in situ Generated $\alpha$-Oxo Gold Carbenes: Efficient Oxidative Union of Allylic Sulfides and Terminal Alkynes via C-C Bond Formation. Chem. Commun. 2014;50(31): 4130-4133. https://doi.org/10.1039/c4CC00739E

136 Ji K, Zhao Y, Zhang L. Optimizing P,N-Bidentate Ligands for Oxidative Gold Catalysis: Efficient Intermolecular Trapping of $\alpha$-Oxo Gold Carbenes by Carboxylic Acids. Angew. Chem. Int. Ed. 2013;52(25): 6508-6512. https://doi.org/10.1002/anie.201301601

${ }^{137}$ Ji K, Zhang L. A Non-Diazo Strategy to Cyclopropanation via Oxidatively Generated Gold Carbene: The benefit of a Conformationally Rigid P,N-Bidentate Ligand. Org. Chem. Front. 2014;1(1): 34-38. https://doi.org/10.1039/C3QO00080J 
${ }^{138}$ Wang Y, Zheng Z, Zhang L. Intramolecular Insertions into Unactivated $\mathrm{C}\left(\mathrm{sp}^{3}\right)-\mathrm{H}$ Bonds by Oxidatively Generated $\beta$-Diketone- $\alpha$-Gold Carbenes: Synthesis of Cyclopentanones. J. Am. Chem. Soc. 2015;137(16): 5316-5419. https://doi.org/10.1021/jacs.5b02280

139 Ji K, Zhang Z, Wang Z, Zhang L. Enantioselective Oxidative Gold Catalysis Enabled by a Designed Chiral P,N-Bidentate Ligand. Angew. Chem. Int. Ed. 2015;54(4): 1245-1249. https://doi.org/10.1002/anie.201409300

${ }^{140}$ Zeineddine A, Rekhroukh F, Sosa-Carrizo ED, Mallet-Ladeira S, Miqueu K, Amgoune A, Bourissou. Isolation of a Reactive Tricoordinate $\alpha$-Oxo Gold Carbene Complex. Angew. Chem. Int. Ed. 2018;57(5): 1306-1310. https://doi.org/10.1002/anie.201711647

${ }^{141}$ Cordero B, Gómez V, Platero-Prats AE, Revés M, Echevarría J, Cremades E, Barragán F, Alvarez S. Covalent Radii Revisited. Dalton Trans. 2008;(21):2832-2838. https://doi.org/10.1039/B801115J

${ }^{142}$ Benitez D, Shapiro ND, Tkatchouk E, Wang Y, Goddard III WA, Toste FD. A Bonding Model for Gold(I) Carbene Complexes. Nat. Chem. 2009;1: 482-486. https://doi.org/10.1038/nchem.331

143 Nunes dos Santos Comprido L, Klein JEMN, Knizia G, Kästner J, Hashmi ASK. The Stabilizing Effects in Gold Carbene Complexes. Angew. Chem. Int. Ed. 2015;54(35): 1033610340. https://doi.org/10.1002/anie.201412401

${ }^{144}$ Xi Y, Su Y, Yu Z, Dong B, McClain EJ, Lan Y, Shi X. Chemoselective Carbophilic Addition of $\alpha$-Diazoesters through Ligand-Controlled Gold Catalysis. Angew. Chem. Int Ed. 2014;53(37): 9817-9821. https://doi.org/10.1002/anie.201404946

${ }^{145}$ Liu Y, Yu Z, Zhang JZ, Liu L, Xia F, Zhang J. Origins of Unique Gold-Catalysed Chemo- and Site-selective C-H Functionalization of Phenols with Diazo Compounds. Chem. Sci. 2016;7(3): 1988-1995. https://doi.org/10.1039/C5SC04319K

${ }^{146}$ García-Morales C, Pei X-L, Sarria Toro JM, Echavarren AM. Direct Observation of Aryl Gold(I) Carbenes that Undergo Cyclopropanation, C-H Insertion, and Dimerization Reactions. Angew. Chem. Int. Ed. 2019;58(12): 3957-3961. https://doi.org/10.1002/anie.201814577

${ }^{147}$ Tskhovreboc AG, Lingnau JB, Fürstner A. Gold Difluorocarbenoid Complexes: Spectroscopic and Chemical Profiling. Angew. Chem. Int. Ed. 2019;58(26): 8834-8838. https://doi.org/10.1002/anie.201903957

${ }^{148}$ Crabtree RH. The Organometallic Chemistry of the Transition Metal. $20044^{\text {th }}$ Ed.; Wiley, Hoboken. 